\title{
Alkaline-Earth Metal Carbonate, Hydroxide and Oxide Nano-Crystals Synthesis Methods, Size and Morphologies Consideration
}

\author{
Mohammad Amin Alavi and Ali Morsali \\ Department of Chemistry, Faculty of Sciences, Tarbiat Modares University \\ Islamic Republic of Iran
}

\section{Introduction}

Inorganic materials are of fundamental interest and technological importance due to their broad application in materials chemistry. It is well documented that the properties of inorganic nano-materials depend strongly on their morphologies, thus, the design and controlled synthesis of nanostructures with different morphological configurations and size distribution on a large scale is very important from the viewpoint of both basic science and technology [1-4]. Barium carbonate $\left(\mathrm{BaCO}_{3}\right)$ is an important mineral as a more thermodynamically stable crystal modification among the heavy metal carbonates and an important material in industry to produce barium salts, pigment, optical glass, ceramic, electric condensers and barium ferrite [5]. Strontium carbonate is an important raw material in modern electronic industry [6] and the glass industry [7]. Furthermore, strontium carbonate has only one crystal-phase, so it has been widely studied as a model system for bio-crystallization [8-13]. $\mathrm{CaO}$ is a material having a wide range of applications, being of continuous interest in the field of materials research. Pure $\mathrm{CaO}$ is an oxide with cubic lattice structure [14] with anisotropic catalytic properties and is often investigated as a component in catalytic powder materials or cements [15]. CaO is also known as dopant able to stabilize cubic zirconia [16] or hafnia [17], and fluently modify the refractive index of silicate glasses [18]. Due to its wide band gap (7.1 eV) [19], high dielectric constant (11.8) [20] and ability to form solid solutions and ternary crystalline phases $\mathrm{CaO}$ and their ternary alloys can be considered as interesting dielectric gate materials, exhibiting high mechanical and radiation resistance [21]. The magnesium oxide $(\mathrm{MgO})$ is a very suitable material for insulation applications due to their low heat capacity and high melting point [22]. Nano-MgO is a functional material that has been widely used in various areas [23, 24]. Recently, it has been reported $[25,26]$ that $\mathrm{MgO}$ has $a$ good bactericidal performance in aqueous environments due to the formation of superoxide $\left(\mathrm{O}_{2}^{-}\right)$anions on its surface. Klabunde and co-workers [27, 28] demonstrated that nano- $\mathrm{MgO}$ exhibits high activity against bacteria, spores and viruses after adsorption of halogen gases because of its large surface area, abundance in crystal defects and positively-charged particles which can result in strong interactions with negatively-charged bacteria and spores [29].

There are different methods for synthesis of these nano-materials and some of them are common. Here we tried to describe a summary of these methods and in the separated section their explanation are expanded one by one. 


\section{2. $\mathrm{BaCO}_{3}$ nanostructures}

$\mathrm{Xu}$ et al. [30] synthesized $\mathrm{BaCO}_{3}$ nanowires in the Triton X-100/cyclohexane/water reverse micelles. Reverse micelle or microemulsion (soft template) is increasingly used to prepare nanowires and nanorods, and works as a microreactor that can compartmentalize reactants at the nanometer level in discrete water. The shape, size and size distribution of nanowires and nanorods prepared by the reverse micelle could be controlled by using different reaction temperature, surfactant, additives, surfactant concentration and mole ratio of water to surfactant $\left(\omega_{0}\right)$ [31]. Triton X-100 (Tx-100) is a nonionic surfactant that forms a nonspherical micelle in cyclohexane. Fig. 1 shows the TEM micrographs of $\mathrm{BaCO}_{3}$ nanowires with different magnifications after aging for $48 \mathrm{~h}$. It can be clearly seen that many wires are disordered pack with length up to several tens of micrometers[30].

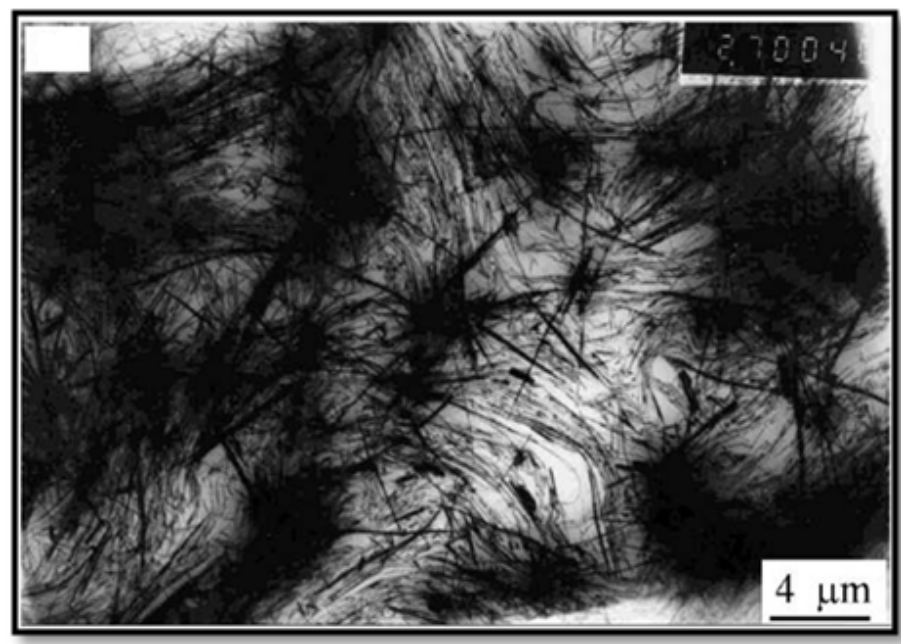

Fig. 1. TEM images of $\mathrm{BaCO}_{3}$ samples formed in Tx-100 reverse micelles [30]. Reproduced with permission of Elsevier.

Microemulsion method was used by Momchilova et al. [32] for preparation nano-sized particles of $\mathrm{BaCO}_{3}$ and microemulsion is applied as a special microreactor to limit the nanosized particles growth. The shape of the microreactor depends on reaction conditions [33]. This method increases the homogeneity of the chemical composition at nano-level and facilitates the preparation of nano-particles with comparatively equal sizes [34]. The specific properties of the nano-particles make them suitable for microelectronics, ceramics, catalysis, medicine, cosmetics, as piezoelectric materials, conductors and etc. Photographs of nanosized particles of $\mathrm{BaCO}_{3}$ are presented in Fig. 2. The nano-particles synthesized were with spherical shape and almost equal sizes varying from 20 to $30 \mathrm{~nm}$. The electron-microscopy analysis revealed that processes of particles agglomeration took place. Since the opalescence observed with the organic phase from the experiments was not very good, the agglomeration was supposed to occur during the electron microscopy analysis itself.

Chu et al. [35] synthesized $\mathrm{BaCO}_{3}$ nanobelts and nanorods by Microemulsion-based method. The introduction of microemulsions has provided a relatively simple and powerful method for controlling the size, shape and surface texture of nanoparticles. In such a 
microenvironment, the nanomaterials are encapsulated into the closed shells of surfactant molecules. The size and shape of nanomaterials could be well controlled by the size of capsules through varying with the different ratios of water and oil. $\mathrm{BaCO}_{3}$ one-dimensional structures were all successfully synthesized in $\mathrm{CTAB} /$ cyclohexane $/ \mathrm{H}_{2} \mathrm{O}$ and $\mathrm{NP}_{10}$ /cyclohexane $/ \mathrm{H}_{2} \mathrm{O}$ microemulsion, respectively. Belt-like $\mathrm{BaCO}_{3}$ nanoparticles were synthesized with solvent hydrothermal treatment. When the $0.18 \mathrm{ml}$ of $0.1 \mathrm{M} \mathrm{Ba}^{2+}$ existed in CTAB microemulsion system, only nanowhiskers of $\mathrm{BaCO}_{3}$ were obtained with $200-400 \mathrm{~nm}$ in length and 10-20 nm in diameter. Concentration of surfactant in the microemulsion is another important parameter that affects the morphology of as-obtained samples. When $\left[\mathrm{NP}_{10}\right]=0.0639$ $\mathrm{M}$, all the samples were composed of nanorods. Increasing value of concentration resulted in the formation of short nanorod of $\mathrm{BaCO}_{3}$ samples. With the increasing of CTAB concentration, the water pool becomes smaller, and the shape changes from rod to ellipsoidal. Solvent hydrothermal treatment of a resulting microemulsion at $140{ }^{\circ} \mathrm{C}$ resulted in the formation of $\mathrm{BaCO}_{3}$ nanobelts with orderly edges, diameter of $200 \mathrm{~nm}$ and length of 1.8-3.4 $\mu \mathrm{m}$ (Fig. 2). The stripes in the nanobelts confirm that the belts are very thin [35].

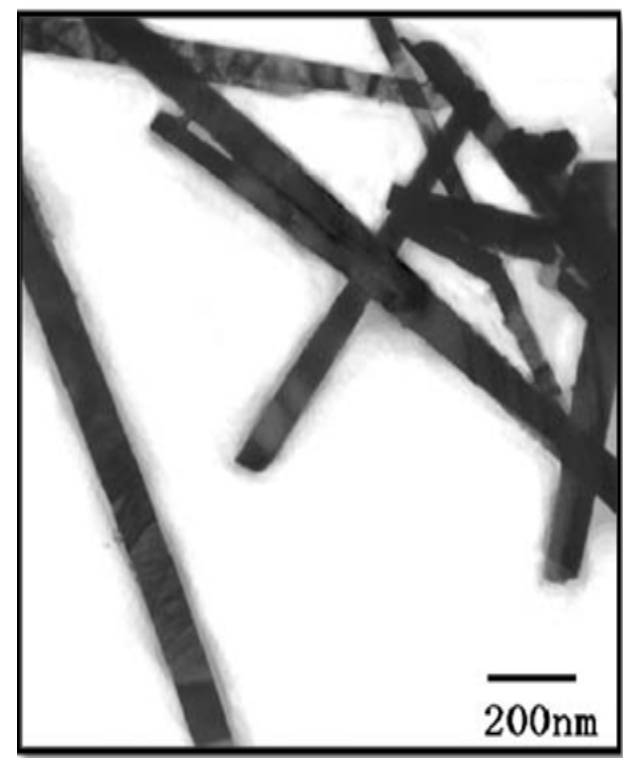

Fig. 2. TEM images of $\mathrm{BaCO}_{3}$ obtained by hydrothermal treating for $12 \mathrm{~h}$. $\left[\mathrm{NP}_{10}\right]=0.127 \mathrm{M}$ and $\mathrm{T}=140{ }^{\circ} \mathrm{C}[35]$. Reproduced with permission of Elsevier.

The barium carbonate nanoparticles were synthesized nanoparticles by flame spray pyrolysis (FSP) [36]. FSP is usually applied for the preparation of metal and metal-oxide nanoparticles [37, 38]. Recently it has been shown that also nanosized salts such as carbonates, phosphates and halogenides can readily be made by flame synthesis [39-41]. The as-prepared material consisted of non-agglomerated crystalline $\mathrm{BaCO}_{3}$ nanoparticles (Fig. 3). TEM analysis further revealed the formation of "bean-like" shaped particles with length of about $100 \mathrm{~nm}$ and width of approximately $50 \mathrm{~nm}$. The corresponding BET-particle diameter for a spherical particle was $70 \mathrm{~nm}$ (specific surface area (SSA): $20.5 \mathrm{~m}^{2} / \mathrm{g}$ ) in good agreement with the TEM observations [36]. 


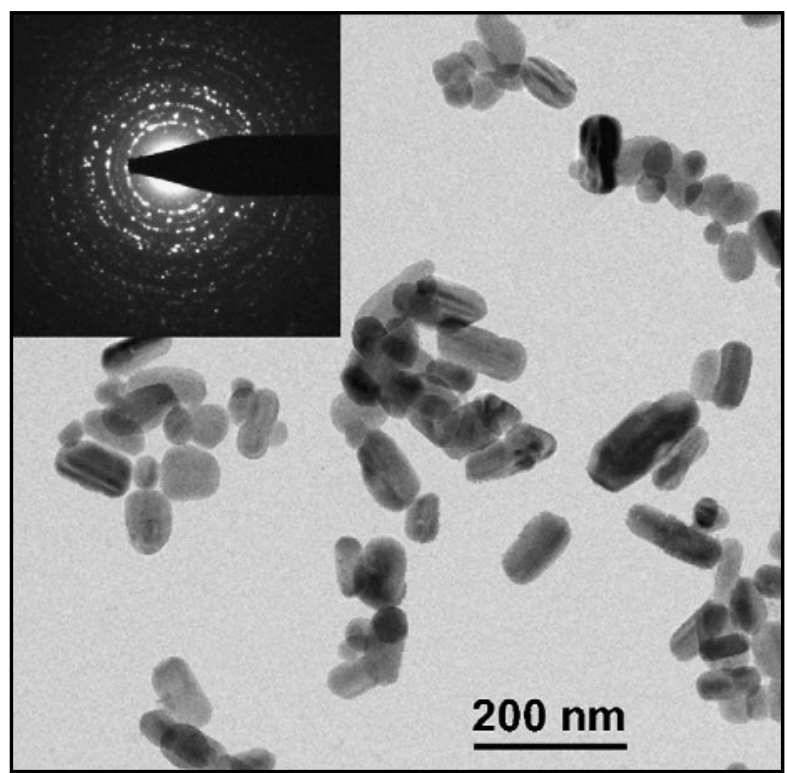

Fig. 3. TEM image and ED pattern (inset) of flame-made $\mathrm{BaCO}_{3}$ nanoparticles [36].

Reproduced with permission of Elsevier.

Sun et al. [5] synthesized single crystalline $\mathrm{BaCO}_{3}$ with different morphologies and sizes by a facile and practicable approach in the presence of polyvinylpyrrolidone (PVP) as a guide reagent at room temperature. Some polymer-assisted syntheses, such as polyacrylic acid (PAA), polyvinyl alcohol (PVA), and polyvinylpyrrolidone (PVP), have been used to prepare a lot of nanomaterials. It is implied that these polymers either changed the surface chemistry of the crystals, or as a guide reagent for crystal growth. Especially, it was found that PVP had excellent effects on the anisotropic growth of Ag, Au nanowires, etc. [42]. The morphologies and microstructure of the as-synthesized products were further investigated by TEM. The bundles of rods, dendritic structures and nanorod morphologies are indeed obtained. The morphology of the bundles of rods (Fig. 4) is similar to the $\mathrm{CeO}_{2}$ prepared by Bai et al., which was described as comet-like [43]. In the process of the reaction, the quantity of $\mathrm{CO}_{3}{ }^{2-}$ increased gradually with the $\mathrm{pH}$ value of the reaction system increasing. Therefore the number of $\mathrm{Ba}^{2+}$ is large relative to $\mathrm{CO}_{3}{ }^{2-}$ under low $\mathrm{pH}$ conditions, and certain facets with relatively higher free energies will preferentially form the active sites and show higher growth rate, thus, the bundles of rods and dendritic structures are obtained, which indicate that the preferential orientation is strongly dependent on the $\mathrm{pH}$ value of the aqueous solution [5].

Zhu et al. [44] synthesized $\mathrm{BaCO}_{3}$ nanostructures in water/ethylene glycol mixed solvents by microwave-assisted method. The EG is a polar solvent which has a reducing ability. It has been widely used in materials synthesis [45-49]. EG is miscible with water at any ratio, and the addition of EG to water can easily change the physicochemical properties. The morphologies of the samples were investigated with SEM and TEM. Fig.5 shows SEM image of the prepared $\mathrm{BaCO}_{3}$ by oil bath heating in water $(10 \mathrm{~mL}) / \mathrm{EG}(10 \mathrm{~mL})$ mixed solvents at $80{ }^{\circ} \mathrm{C}$ for $30 \mathrm{~min}$., from which one can see $\mathrm{BaCO}_{3}$ nanorods with diameters of 


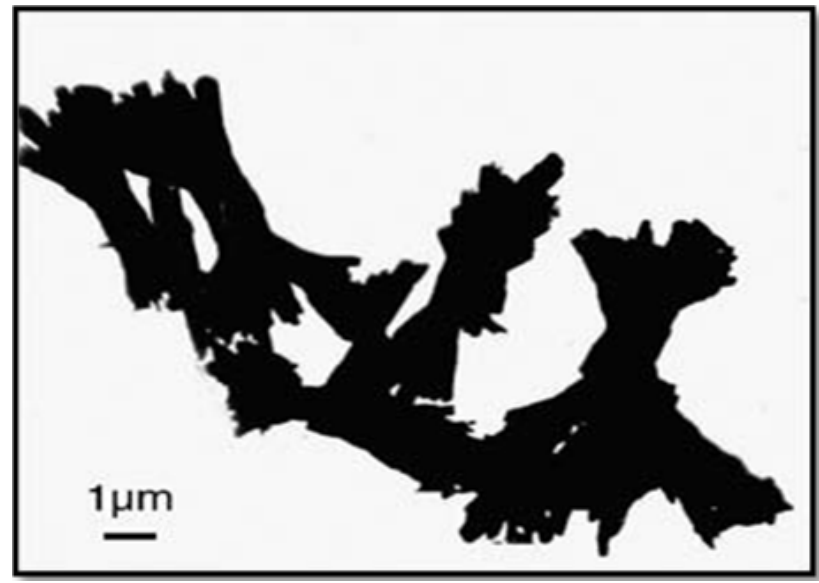

Fig. 4. TEM images of synthesized $\mathrm{BaCO}_{3}$ by PVP-assisted method at $\mathrm{pH}=12$ [5]. Reproduced with permission of Elsevier.

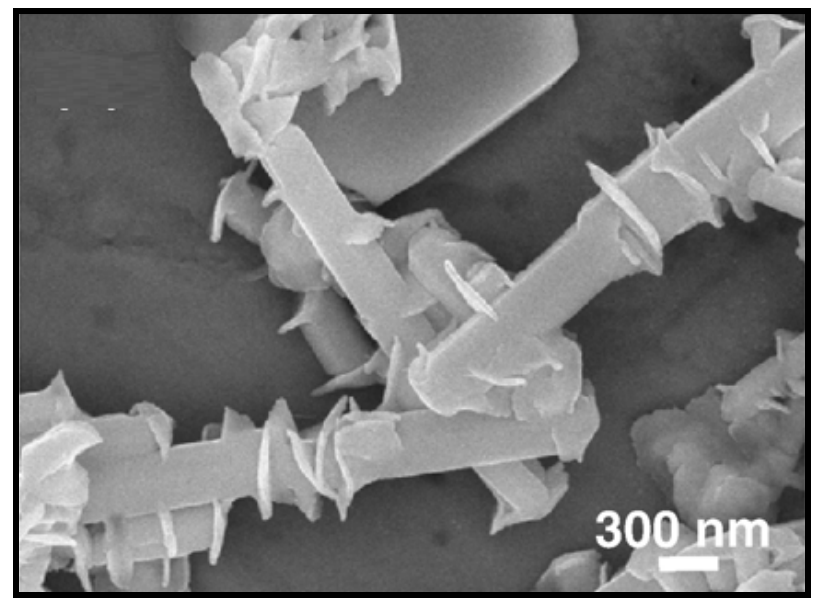

Fig. 5. SEM image of as prepared $\mathrm{BaCO}_{3}$ powder by oil bath heating in water $(10 \mathrm{~mL}) / \mathrm{EG}$ $(10 \mathrm{~mL})$ mixed solvents at $80^{\circ} \mathrm{C}$ for $30 \mathrm{~min}$ [44]. Reproduced with permission of Elsevier.

about $250 \mathrm{~nm}$ and lengths of about $1 \mu \mathrm{m}$. It is interesting that the nanosheets grew perpendicularly on the nanorods. The sizes of $\mathrm{BaCO}_{3}$ nanorods were relatively uniform. [44]. $\mathrm{BaCO}_{3}$ nanostructures was also fabricated by liquid phase precipitation method [50]. The liquid phase precipitation method is one of the earliest methods for the synthesis of inorganic particles. V. K. Lamer et al. [51] reported the synthesis of monodisperse colloidal sulfur in ethanol/water mixed solvents in 1950. After that, the application of this method in the synthesis of inorganic materials has been fast growing [52]. The precipitation reactions involve the nucleation, growth, ripening, or agglomeration processes. The separation of nucleation and growth is the key step for the preparation of high quality crystals. The growth mechanism, such as Ostwald ripening [53-55] and aggregation especially oriented 
attachment [56, 57], will dramatically affect the size, morphology, and properties of the products. In the Ostwald ripening process [53-55], the larger particles will grow at the expense of the smaller ones. The "oriented attachment" mechanism was reported by Penn and Banfield [56, 57]. Fig. 6a shows TEM image of the sample prepared using $\mathrm{NaHCO}_{3}$ as the $\mathrm{CO}_{3}{ }^{2-}$ source, from which one can see $\mathrm{BaCO}_{3}$ rods with diameters of several hundred nanometers and lengths of several micrometers. When $\mathrm{Na}_{2} \mathrm{CO}_{3}$ was used as the $\mathrm{CO}_{3}{ }^{2-}$ source the rods and nanoparticles co-existed. When using $\left(\mathrm{NH}_{4}\right)_{2} \mathrm{CO}_{3}$ as the $\mathrm{CO}_{3}{ }^{2-}$ source, a completely different shape (bundle and flower) of $\mathrm{BaCO}_{3}$ was observed. These $\mathrm{BaCO}_{3}$ bundles and flowers were assembled from nanosheets. These results indicate that the type of $\mathrm{CO}_{3}{ }^{2-}$ source has an influence not only on the crystallinity of $\mathrm{BaCO}_{3}$, but also on the morphology of $\mathrm{BaCO}_{3}$. In the aqueous solution, $\mathrm{Na}_{2} \mathrm{CO}_{3}$ is a relatively strong base, and $\left(\mathrm{NH}_{4}\right)_{2} \mathrm{CO}_{3}$ is a weak base. The $\mathrm{pH}$ of the solution has an influence on the nucleation and growth of $\mathrm{BaCO}_{3}$. This may explain the different morphologies of $\mathrm{BaCO}_{3}$ obtained using different $\mathrm{CO}_{3}{ }^{2-}$ sources. They also investigated the effect of the surfactant on the morphology of $\mathrm{BaCO}_{3}$. When P123 was used, more dense flowers were observed. When SDBS was used the major morphology was bundle-like, and some fragments were also observed as a minor morphology. When CTAB was used, the loosely assembled flowers were obtained (Fig. 6b). Therefore, the type of the surfactant has an effect on the morphology of $\mathrm{BaCO}_{3}$.

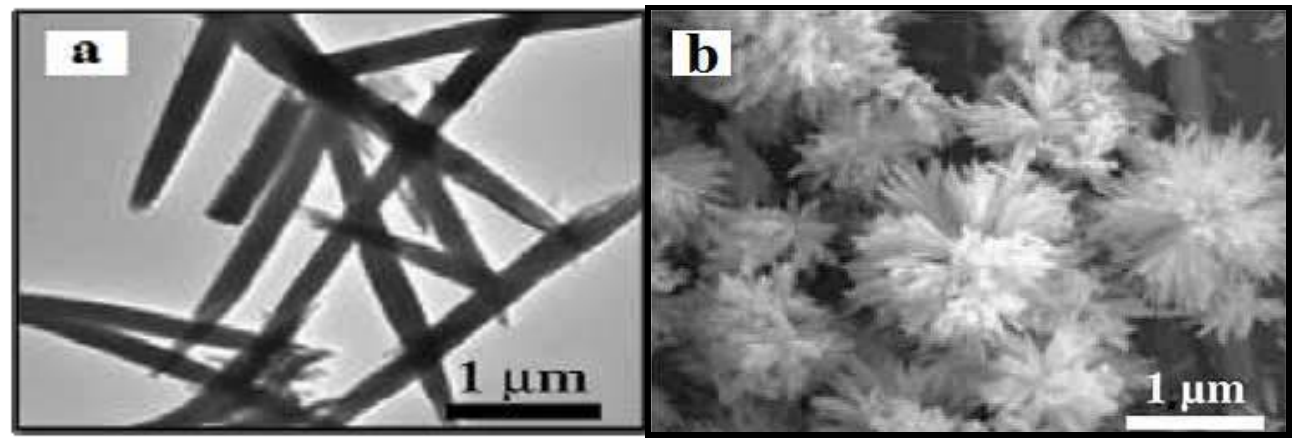

Fig. 6. a) TEM images of as prepared $\mathrm{BaCO}_{3}$ nanostructures by liquid phase precipitation method using a) $\mathrm{NaHCO}_{3}$ as the $\mathrm{CO}_{3}{ }^{2-}$ source and b) SEM images of the sample prepared using $20 \mathrm{~mL}$ CTAB $(9.100 \mathrm{~g} / \mathrm{L})$ [50]. Reproduced with permission of Elsevier.

In recent our work [58] ultrasound irradiation was used for synthesis of $\mathrm{BaCO}_{3}$ nanostructures. Sonochemical synthesis has been used in the preparation of many materials [59-86]. Ultrasound induces chemical changes due to cavitation phenomena involving the formation, growth, and instantaneously implosive collapse of bubbles in liquid, which can generate local hot spots having a temperature of roughly $5000{ }^{\circ} \mathrm{C}$, pressures of about 500 atm, and a lifetime of a few microseconds [87]. These extreme conditions can drive chemical reactions such as oxidation, reduction, dissolution, and decomposition, which have been developed to fabricate a variety of metal, oxide, sulfide, and carbide nanoparticles [88-92]. The morphology, structure and size of the samples are investigated by Scanning Electron Microscopy (SEM). Fig. 7a shows SEM image of as prepared $\mathrm{BaCO}_{3} 1 \mathrm{D}$ nanostructures that concentration of $\mathrm{Ba}^{2+}$ ion was $0.1 \mathrm{M}$, the power of ultrasound device was $30-60 \mathrm{~W}$ and the sonication time was $1 \mathrm{~h}$. As we described [58] there are three parameters that we changed 
and the best morphology, size and good distribution was obtained for the above sample (Fig. 7a). As illustrated in Fig. 7b we tried to synthesize better nanorods of $\mathrm{BaCO}_{3}$ so we used 2g PVA (Polyvinyl Alcohol) as stabilizer in the same condition as Fig.7a and so we can gain the nanorods with approximately $95 \mathrm{~nm}$ width and about $1 \mu \mathrm{m}$ length.
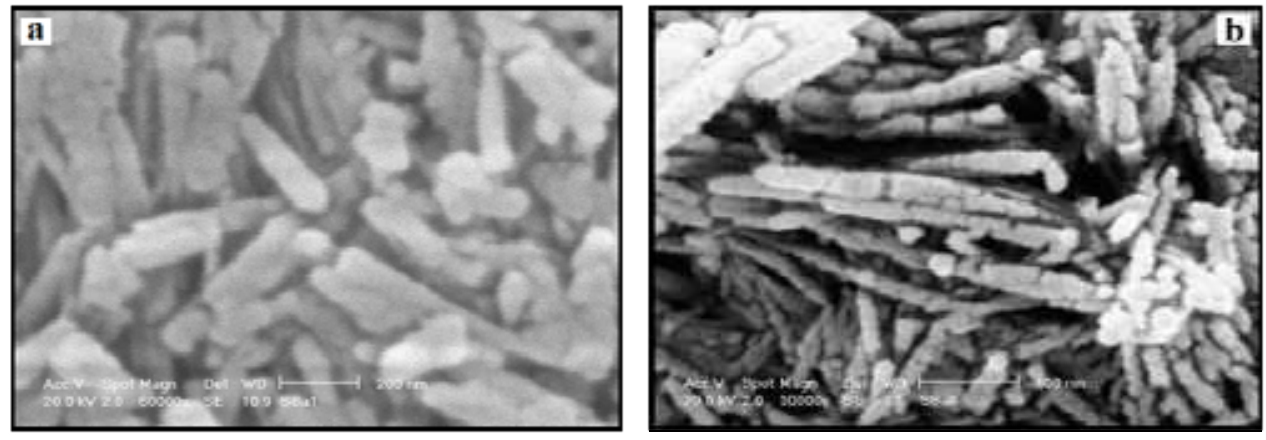

Fig. 7. SEM images of as prepared $\mathrm{BaCO}_{3} 1 \mathrm{D}$ nanostructure by sonochemical method a) without PVA and $b$ ) in the presence of $2 \mathrm{~g}$ PVA [58]. Reproduced with permission of Elsevier.

Chen et al. [93] synthesized thorny $\mathrm{BaCO}_{3}$ dendritic structures via a simple PEG-assisted method. They reported that low molecular weight polyethylene glycol (PEG), $M_{\mathrm{w}} 1000 \mathrm{~g}$ mol-1 $^{-1}$, could be used for the self-assembly of complex $\mathrm{BaCO}_{3}$ superstructures through a facile mineralization process under ambient conditions. SEM images of synthesized $\mathrm{BaCO}_{3}$ nanostructures illustrated in Fig. 8 shows the influence of the amount of PEG on morphologies of $\mathrm{BaCO}_{3}$ particles at $40{ }^{\circ} \mathrm{C}$ after $72 \mathrm{~h}$ under the synthesis condition. Bundles of rods structures $\mathrm{BaCO}_{3}$ were observed in the control experiments without adding polymer additives (Fig. 8a). However, when the amount of PEG is increased to $0.2,1$, and $1.5 \mathrm{~g} \mathrm{~L}^{-1}$, the bole becomes longer and the branches become shorter, and there are many small thorns on the surface. When the amount of PEG becomes larger (from 0.2 to $1.5 \mathrm{gL}^{-1}$ ), the thorns become more (Fig. 8b), typical for the interaction between the hydroxy group of PEG and the crystallizing $\mathrm{BaCO}_{3}$, which effectively suppresses the branch crystal growth [93].

The effects of reaction time and citric acid contents on the morphologies of $\mathrm{BaCO}_{3}$ via PVPassisted method was studied by Sun et al. [94]. Usually, organic additives and/or templates with complex functionalization patterns can control crystal growth via face selective adsorption. Therefore, to extend the application of $\mathrm{BaCO}_{3}$ and to deepen the comprehension of its crystal growth behaviors, it is necessary to have a suitable choice of "capping reagent" possessing both stability and simplicity for the preparation of $\mathrm{BaCO}_{3}$ with distinguished shapes and especially good uniformity. It is generally accepted that the coordination reagent kinetically controls the growth rates of various faces of nanocrystals through selective adsorption and desorption on these surfaces [95]. It implied that these polymers either changed the surface chemistry of the crystals, or as a guide reagent for crystal growth. Moreover, PVP in their experimental procedures may also serve as a stabilizer, which inhibits $\mathrm{BaCO}_{3}$ particles from aggregating. The morphologies and microstructure of the assynthesized products were further investigated by TEM. The products with dumbbell and pillar morphologies are obtained with $\mathrm{pH} 13$, citric acid (CA) $/ \mathrm{Ba}^{2+}=4$ and a reaction time of 


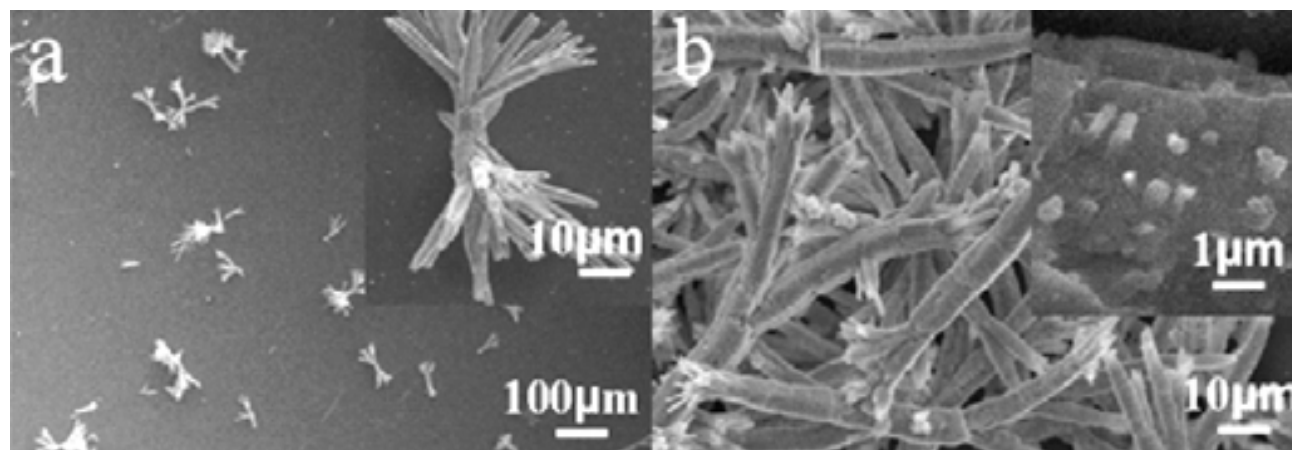

Fig. 8. SEM images of as prepared $\mathrm{BaCO}_{3}$ dendritic structures via a PEG-assisted method at $40{ }^{\circ} \mathrm{C}$ after $72 \mathrm{~h} \mathrm{a}$ ) without PEG and b) presence of $0.2 \mathrm{~g} \mathrm{~L}^{-1}$ PEG [93]. Reproduced with permission of Elsevier.

$15 \mathrm{~min}, 2 \mathrm{~h}, 8 \mathrm{~h}$. Reaction time seems an important factor that can affect the morphology of the products. As shown in Fig. 11a, the products with dumbbell morphology, smooth surface and uniform size distribution were obtained at $15 \mathrm{~min}$, just like being placed in an orderly arrangement. When the reaction time is prolonged, the products with pillar morphology appear with a length of several hundred nanometers. The size of the particles was decreased gradually with reaction time, the phenomenon may be attributed to the partial dissolution of the particles. The products with different morphologies can be synthesized through controlling the molar ratio of citric acid to the concentration of the $\mathrm{Ba}^{2+}$ ions. Increasing $\mathrm{CA} / \mathrm{Ba}^{2+}$ results in more carboxylic groups, when the molar ratio of $\mathrm{CA}$ to $\mathrm{Ba}^{2+}$ rises up to 5 and the other conditions are kept the same, the products with dumbbell-, double-pillar- and pillar-like are obtained at different times. The products with homogeneous dumbbell-like morphology were obtained at $15 \mathrm{~min}$ (Fig. 9b). It is clearly shown that the middle bending of dumbbell is small relative to those in Fig. 9a. When the reaction time is prolonged to $2 \mathrm{~h}$, the products with double-pillar-like morphology appear with a length of 280-420 $\mathrm{nm}$ [94].

Thongtem et al. [96] used sonochemical method for synthesis of $\mathrm{BaCO}_{3}$ nanoparticles. TEM images and SAED patterns of $\mathrm{BaCO}_{3}$ are shown in Fig. 10. TEM shows that the products were composed of dispersed round nanoparticles with the sizes of $40-100 \mathrm{~nm}$ for $\mathrm{BaCO}_{3}$ (as illustrated in fig 10). Their SAED patterns appear as diffuse and hollow concentric rings of bright spots, caused by the diffraction of transmitted electrons through the nanocrystals with different orientations. Interplanar spaces were calculated using diameters of the diffraction rings [97], and compared with those of the JCPDS database [98]. They correspond to the (111), (002), (112), (221), (132) and (113) planes for $\mathrm{BaCO}_{3}$. Their sizes were measured from 150 particles on TEM images. The products were synthesized in all sizes, ranging from the smallest to the largest with the average of $55.20 \pm 9.60 \mathrm{~nm}, 65.00 \pm 10.04 \mathrm{~nm}$ and $89.56 \pm 16.10 \mathrm{~nm}$ for $\mathrm{BaCO}_{3}$ by the $1 \mathrm{~h}, 3 \mathrm{~h}$ and $5 \mathrm{~h}$ ultrasonic irradiation, respectively. To form $\mathrm{BaCO}_{3}$ nanoparticles, $\mathrm{Ba}\left(\mathrm{NO}_{3}\right)_{2}$ reacted with $\mathrm{Na}_{2} \mathrm{CO}_{3}$ in ethylene glycol (EG) under ultrasonic irradiation. Once the $\mathrm{BaCO}_{3}$ nuclei formed in ethylene glycol by the assistance of ultrasonic irradiation, they did not fully develop. They grew into a number of nanoparticles via the diffusion process in EG. These nanoparticles became larger when the lengths of times were longer. They were still retaining their nanosize, although the reaction time was lengthened to $5 \mathrm{~h}[96]$. 

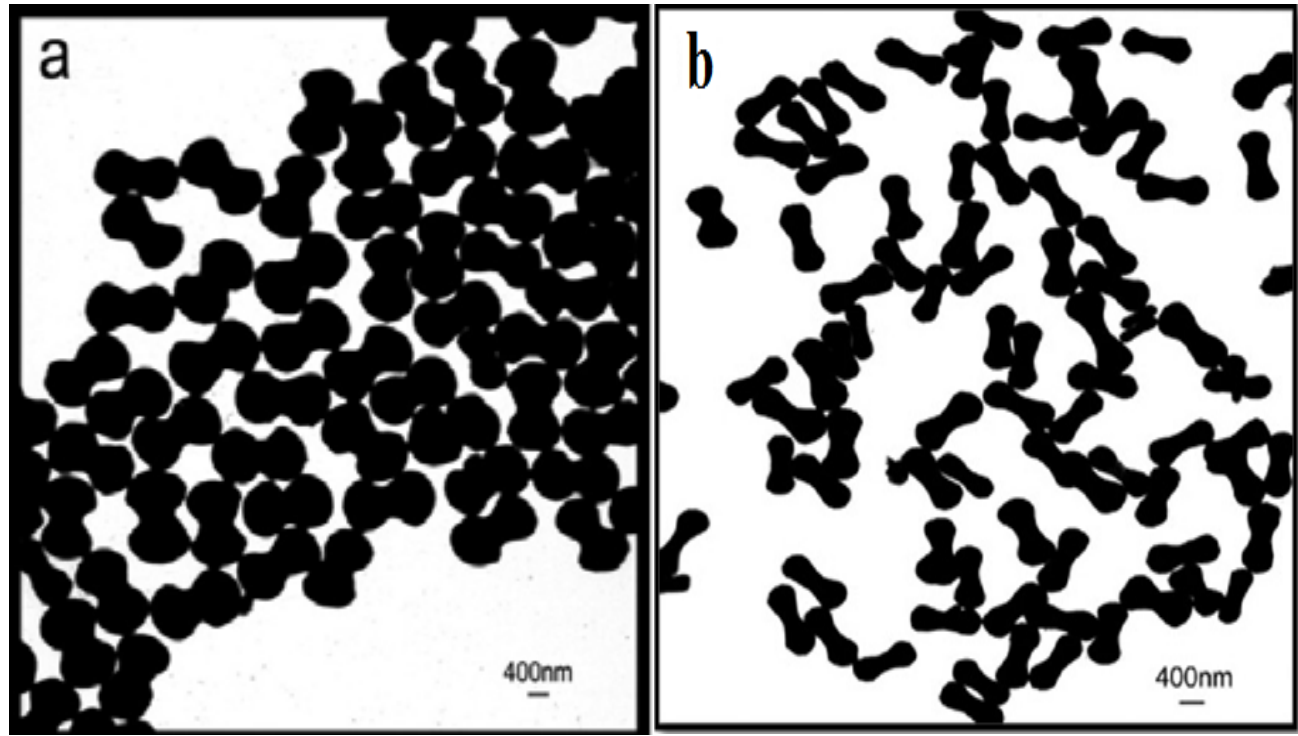

Fig. 9. TEM images of as prepared $\mathrm{BaCO}_{3}$ nanostructures via $\mathrm{PVP}$-assisted method with $\mathrm{pH}$ 13 , at reaction times $=15 \min (\mathrm{a}) \mathrm{CA} / \mathrm{Ba}^{2+}=4$ and b) $\mathrm{CA} / \mathrm{Ba}^{2+}=5$ [94]. Reproduced with permission of Elsevier.

\section{3. $\mathrm{SrCO}_{3}$ and $\mathrm{Sr}(\mathrm{OH})_{2}$ nanostructures}

$\mathrm{Hu}$ et al. [99] synthesized $\mathrm{SrCO}_{3}$ nanostructures by Microemulsion-Mediated Solvothermal method. A reverse micelle or microemulsion is a transparentand isotropic liquid medium with nanosized water pools dispersed in a continuous phase and stabilized by surfactant, for example, cationic surfactant $\mathrm{CTAB}$ (cetyltrimethylammonium bromide), anionic surfactant AOT (sodium bis(2-ethylhexyl) sulfosuccinate) or nonionic surfactant Triton- 100 (octylphenol-poly(ethylene glycol) ether), and cosurfactant (such as 1-pentanol or 1-butanol) molecules at the water/oil interface. Accordingly, reverse micelles or microemulsions that are thermodynamically stable systems and isotropic on a molecular scale have the ability to solubilize proper solution. As the nanosized water pools, they have been widely used as spatially constrained microreactors for controlled synthesis of nanoparticles with a desired narrow size distribution. They reported the synthesis of $\mathrm{SrCO}_{3}$ nanostructures with various morphologies in a simple cationic surfactant-CTAB-microemulsion system under solvothermal conditions. By carefully controlling fundamental experimental parameters such as the molar ratio $\mathrm{H}_{2} \mathrm{O}$ to $\mathrm{CTAB}$ (defined $w$ ) and the concentration of reactants, $\mathrm{SrCO}_{3}$ nanostructures with morphologies of rodlike, whiskerlike, ellipsoidlike, and spherelike can be efficiently achieved. Fig.11 shows a typical TEM image of obtained $\mathrm{SrCO}_{3}$ nanorods and also the growth mechanism of $\mathrm{SrCO} 3$ nanostructures [99].

Mesoporous $\mathrm{SrCO}_{3}$ spheres in room-temperature ionic liquid was reported [100]. Room temperature ionic liquids (ILs), which are liquid organic salts at room temperature, have been very attractive in both academia and industry because of their special characteristics, such as a negligible vapor pressure, wide liquid temperature range, thermal stability, high conductivity, etc., and they are regarded as environmentally benign solvents [101]. TEM image in Fig. 12a 
includes a number of $\mathrm{SrCO}_{3}$ spheres, and the high-magnification TEM image (Fig. 12b) indicates that the spheres are composed of nanoparticles, which form the special loose

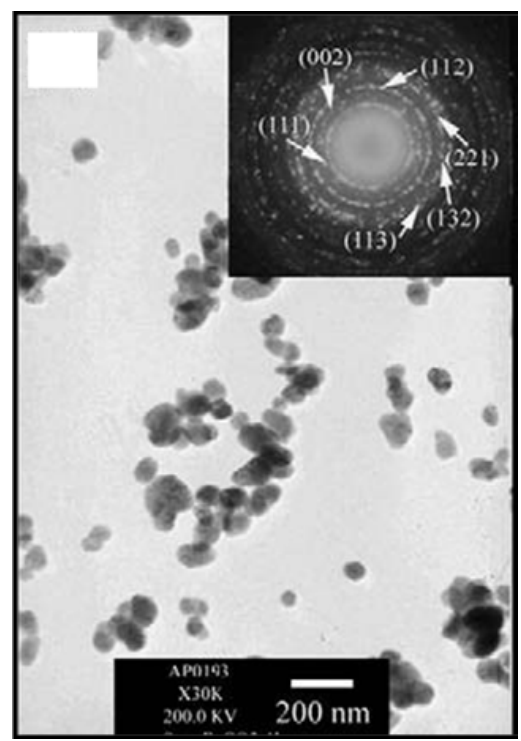

Fig. 10. TEM images and SAED patterns of as synthesized $\mathrm{BaCO}_{3}$ by sonochemical method at $80^{\circ} \mathrm{C}$ for $1 \mathrm{~h}$ [96]. Reproduced with permission of Elsevier.

Yang et al. [102] synthesized flower-like $\mathrm{SrCO}_{3}$ nanostructures by hydrothermal method. The morphology of the products characterized by field emission scanning electron microscopy (FESEM) is shown that most of the flower-like nanostructures consist of $\mathrm{SrCO}_{3}$ nanorod bundles. The TEM characterization of the above-mentioned sample was shown in Fig. 13. The morphology of flowerlike $\mathrm{SrCO}_{3}$ nanostructures consisting of nanorods with diameter of 100-300 nm and length of about several micrometres is observed from Fig. 13.

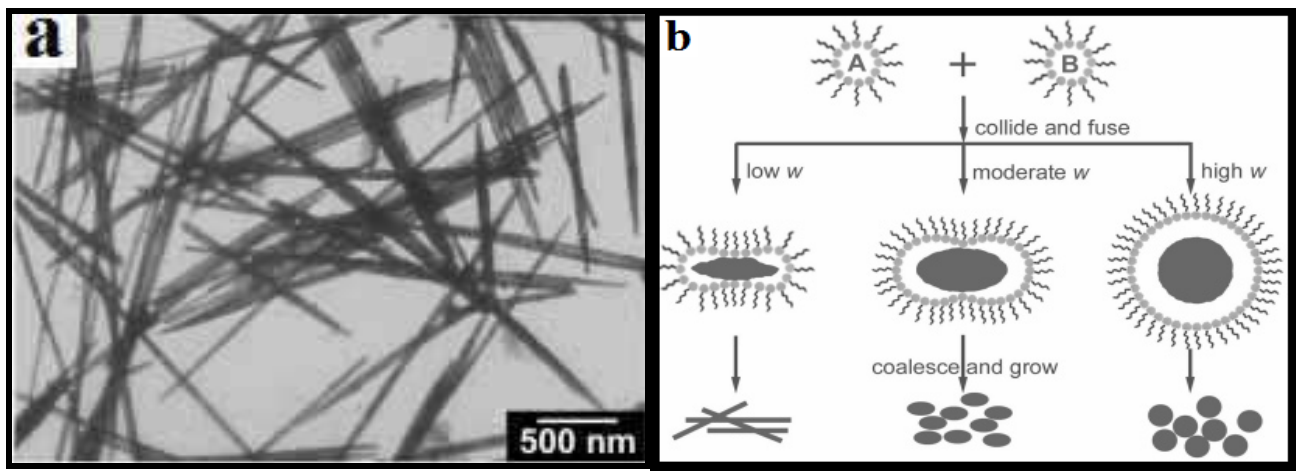

Fig. 11. a) TEM image of obtained $\mathrm{SrCO}_{3}$ nanorods at $w=5$ and $\mathrm{Sr}\left(\mathrm{NO}_{3}\right)_{2}$ concentration of 0.5 $\mathrm{M}$ and b) the growth mechanism of $\mathrm{SrCO}_{3}$ nanostructures [99]. Reproduced with permission of American Chemical Society. 


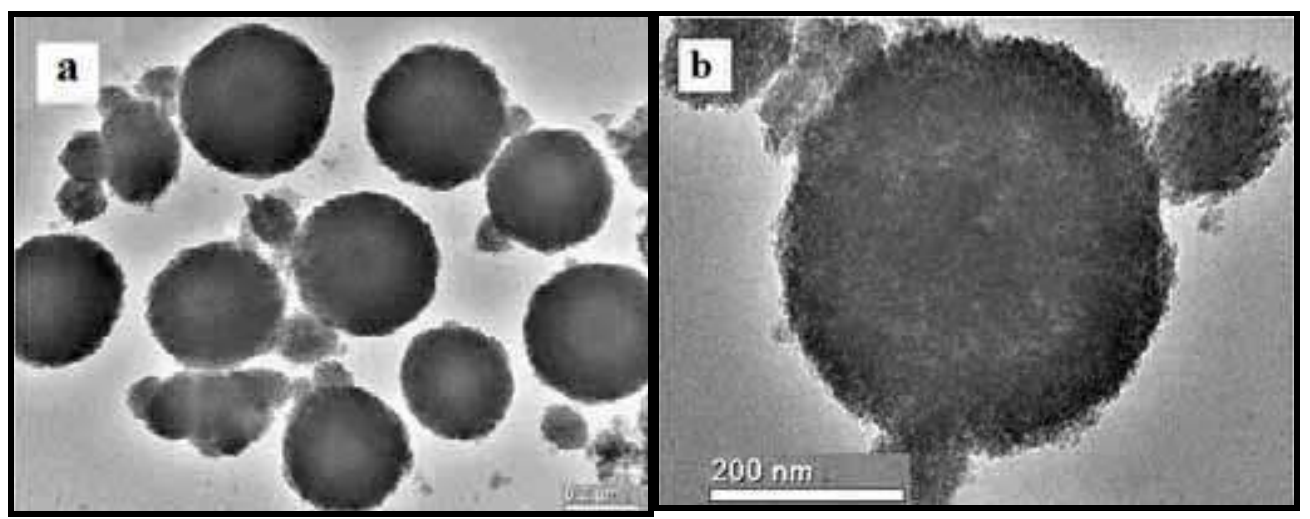

Fig. 12. a) TEM image of the obtained $\mathrm{SrCO}_{3}$, b) typical TEM image of mesoporous $\mathrm{SrCO}_{3}$ spheres with high magnification [100]. Reproduced with permission of Elsevier.

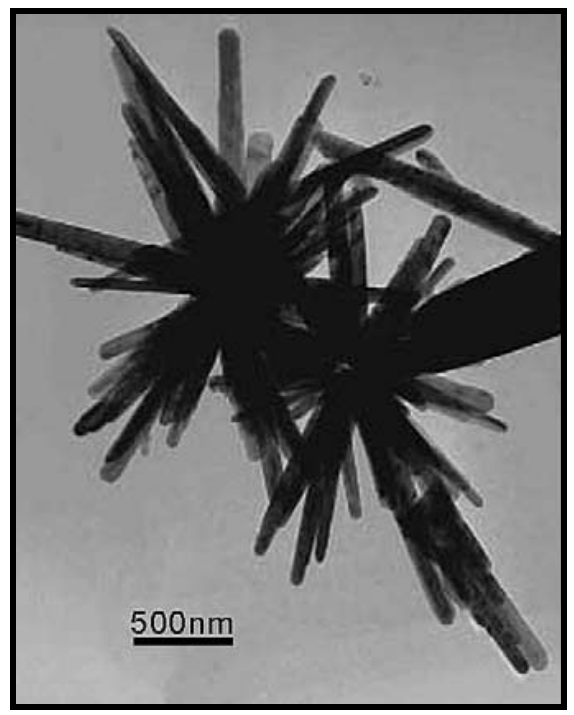

Fig. 13. TEM image of the flower-like $\mathrm{SrCO}_{3}$ nanostructures synthesized by the hydrothermal process at $200^{\circ} \mathrm{C}$ [102]. Reproduced with permission of Elsevier.

Yu et al. [103] investigated on the shape evolution of $\mathrm{SrCO}_{3}$ particles in the presence of poly(styrene-alt-maleic acid). PSMA was used as a crystal modifier to adjust the morphology of $\mathrm{SrCO}_{3}$ particles by varying the concentration of PSMA. It was found that different shapes of $\mathrm{SrCO}_{3}$ particles could be successfully obtained. Fig. 14 shows SEM micrographs of $\mathrm{SrCO}_{3}$ particles obtained from aqueous solution in the absence and presence of PSMA at room temperature. It could be seen from Fig. 14a that, in the absence of PSMA, the as-obtained particles appeared bundle-like aggregates consisting of many small $\mathrm{SrCO}_{3}$ needles aligned radially towards both ends. Further observation showed that there existed many fragments ruptured at the middle parts of the bundles. Therefore, it could be inferred that the middle 
parts of the bundles were more fragile than their radial branches. When a small amount of PSMA $\left(0.01 \mathrm{gL}^{-1}\right)$ was added into the reaction system, the morphology of $\mathrm{SrCO}_{3}$ particles obviously changed (as shown in Fig. 14b).
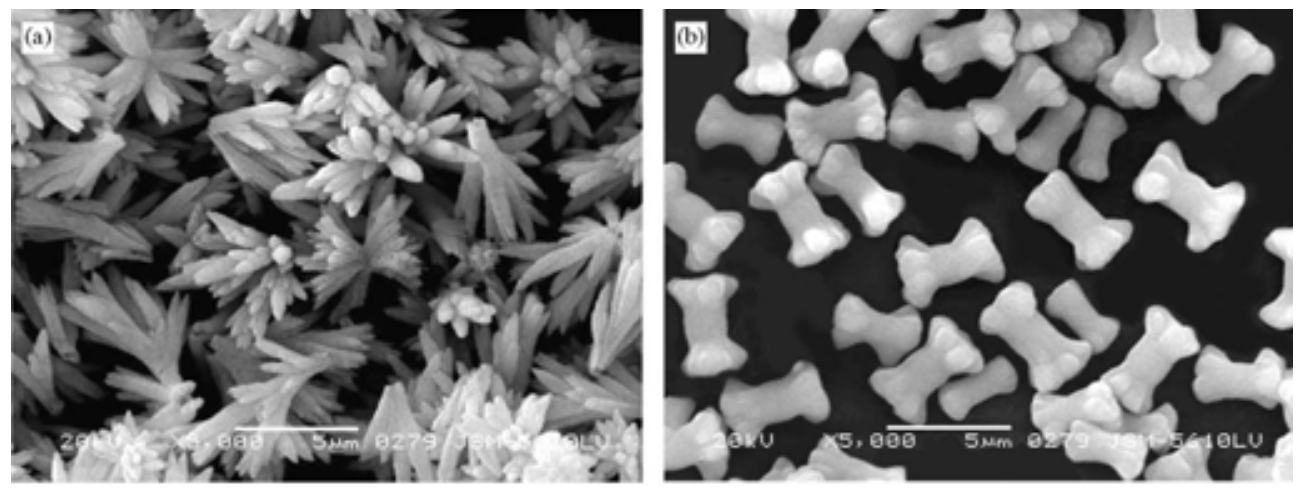

Fig. 14. SEM images of $\mathrm{SrCO}_{3}$ particles obtained in the presence of PSMA at room temperature, [ $\left.\mathrm{SrCO}_{3}\right]=2 \mathrm{mM}, \mathrm{pH}=10$ a) without PSMA and b) $0.01 \mathrm{gL}^{-1}$ PSMA [103]. Reproduced with permission of Elsevier.

One-dimensional $\mathrm{SrCO}_{3}$ nanostructures were prepared and characterized by Microwave method [104]. In this work ethylenediamine (EDA) as a coordination molecular template was used for synthesis of $\mathrm{SrCO}_{3}$ nanostructures. The main advantages of microwave heating are rapid volumetric heating, fast heating rate, and short reaction time, leading to new routes to realize materials synthesis in a short time. Fig. 15a shows SEM images of the typical branch-like morphology of $\mathrm{SrCO}_{3}$ and fig. $15 \mathrm{~b}$ shows the top view of the hexagonal cone, from which one can clearly see the six crystal planes [104].
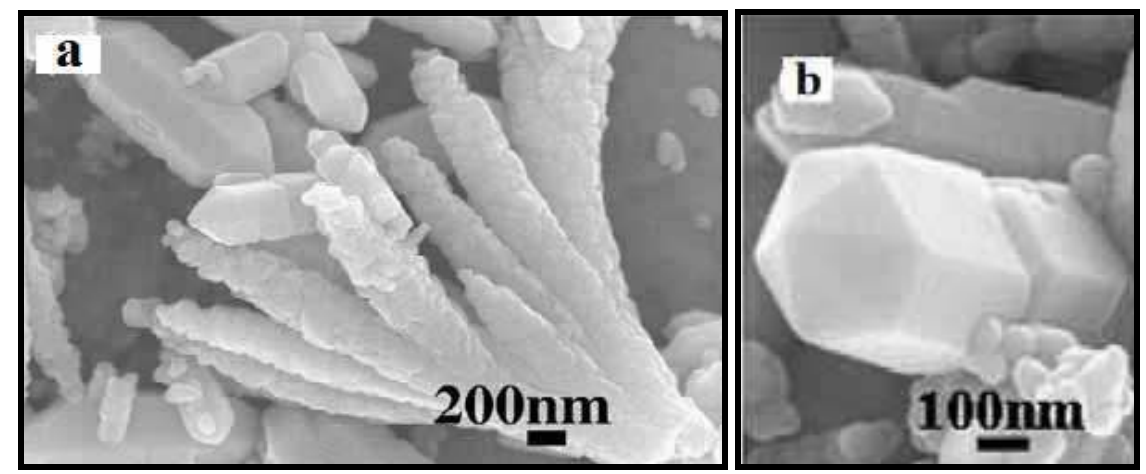

Fig. 15. SEM images of $\mathrm{SrCO}_{3}$ prepared by microwave heating an aqueous solution of $\left(\mathrm{NH}_{4}\right)_{2} \mathrm{CO}_{3}, \mathrm{Sr}\left(\mathrm{NO}_{3}\right)_{2}$ and EDA at $90^{\circ} \mathrm{C}$ for a) $40 \mathrm{~min}$ and b) $5 \mathrm{~min}$ [104]. Reproduced with permission of Elsevier.

Huang et al. [105] investigated on crystallization of strontium carbonate in alcohol or water solution containing mixed nonionic/anionic surfactants. They use Pluronic F127 $\left(\mathrm{EO}_{97} \mathrm{PO}_{68} \mathrm{EO}_{97}\right)$ and sodium dodecyl sulfate (SDS). Fig. 16 shows SEM images of $\mathrm{SrCO}_{3}$ 
nanostructures in the presence of surfactant [105]. Comparing with SEM images of obtained product in the present and absence of surfactant F127, it has little effect on morphology of product (as shown in fig. 16a) but by adding the $0.02 \mathrm{M}$ SDS to the reaction the morphology changes as illustrated in fig $16 \mathrm{~b}$.

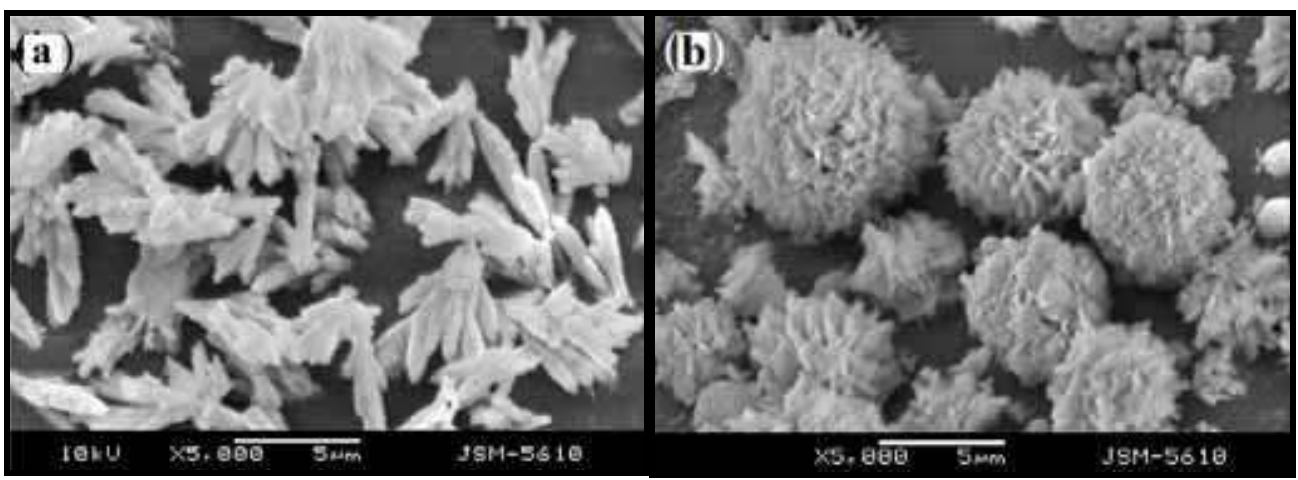

Fig. 16. SEM images of samples produced in aqueous solution a) in the presence of $2.0 \mathrm{~g} / \mathrm{L}$ F127 and b) in the presence of $2.0 \mathrm{~g} / \mathrm{L}$ F127/0.02 M SDS [105]. Reproduced with permission of Elsevier.

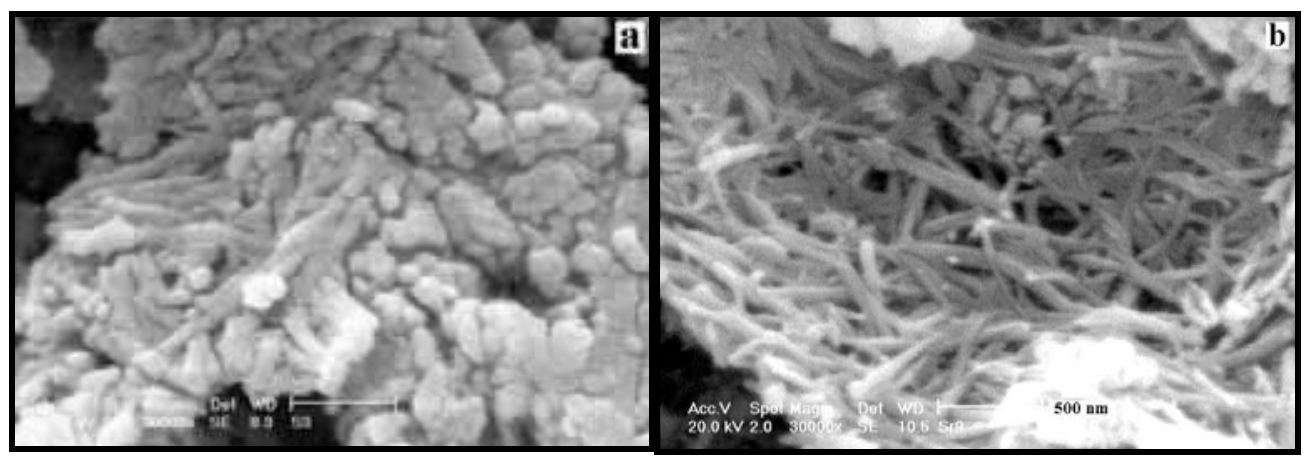

Fig. 17. SEM images of the mixture of $\mathrm{Sr}(\mathrm{OH})_{2}$ and $\mathrm{SrCO}_{3}$ nanoparticles $\left[\mathrm{Sr}\left(\mathrm{CH}_{3} \mathrm{COO}\right)_{2}\right]=0.1$ $\mathrm{M}$, Sonication time $=2 \mathrm{~h}$ a) Power of ultrasound device $=30-60 \mathrm{~W}$ and $\mathrm{b}$ ) presence of $1 \mathrm{~g}$ $\mathrm{NaNO}_{3}$ and Power of ultrasound device $=120-150 \mathrm{~W}$ [106]. Reproduced with permission of Elsevier.

Nanostructures of the mixture of $\mathrm{Sr}(\mathrm{OH})_{2}$ and $\mathrm{SrCO}_{3}$ were prepared by sonochemical method [106]. Our search shows that there is no report for synthesis of $\operatorname{Sr}(\mathrm{OH})_{2}$ nanostructures and this is the first report. Fig. 17 shows SEM images of obtained mixture of $\mathrm{Sr}(\mathrm{OH})_{2}$ and $\mathrm{SrCO}_{3}$. When the sonication time increases to $2 \mathrm{hr}$ nanoparticles aggregate and grow to prepare 1D nanostructures (fig. 17a). For synthesis of 1D nanostructures we used $\mathrm{NaNO}_{3}$ as an alkali salt and as it has been shown in fig. $17 \mathrm{~b}$ the nanorods of $\mathrm{Sr}(\mathrm{OH})_{2}$ and $\mathrm{SrCO}_{3}$ with suitable length are produced.

Thongtem et al. [96] used sonochemical method for synthesis of $\mathrm{SrCO}_{3}$ nanoparticles. TEM shows that the products were composed of dispersed round 128 nanoparticles with the sizes 
of 20-50 nm for $\mathrm{SrCO}_{3}$ (fig. 18). Their SAED patterns appear as diffuse and hollow concentric rings of bright spots, caused by the diffraction of transmitted electrons through the nanocrystals with different orientations. Interplanar spaces were calculated using diameters of the diffraction rings [97], and compared with those of the JCPDS database [98]. They correspond to the (111), (002), (112), (221), (132) and (113) planes for $\mathrm{SrCO}_{3}$. Their sizes were measured from 150 particles on TEM images. The products were synthesized in all sizes, ranging from the smallest to the largest with the average of $29.83 \pm 4.26 \mathrm{~nm}, 34.02 \pm 5.26$ $\mathrm{nm}$ and $37.20 \pm 5.86 \mathrm{~nm}$ for $\mathrm{SrCO}_{3}$ by the $1 \mathrm{~h}, 3 \mathrm{~h}$ and $5 \mathrm{~h}$ ultrasonic irradiation, respectively. To form $\mathrm{SrCO}_{3}$ nanoparticles, $\mathrm{Sr}\left(\mathrm{NO}_{3}\right)_{2}$ reacted with $\mathrm{Na}_{2} \mathrm{CO}_{3}$ in ethylene glycol (EG) under ultrasonic irradiation. Once the $\mathrm{SrCO}_{3}$ nuclei formed in ethylene glycol by the assistance of ultrasonic irradiation, they did not fully develop. They grew into a number of nanoparticles via the diffusion process in EG. These nanoparticles became larger when the lengths of times were longer. They were still retaining their nanosize, although the reaction time was lengthened to $5 \mathrm{~h} \mathrm{[96].}$

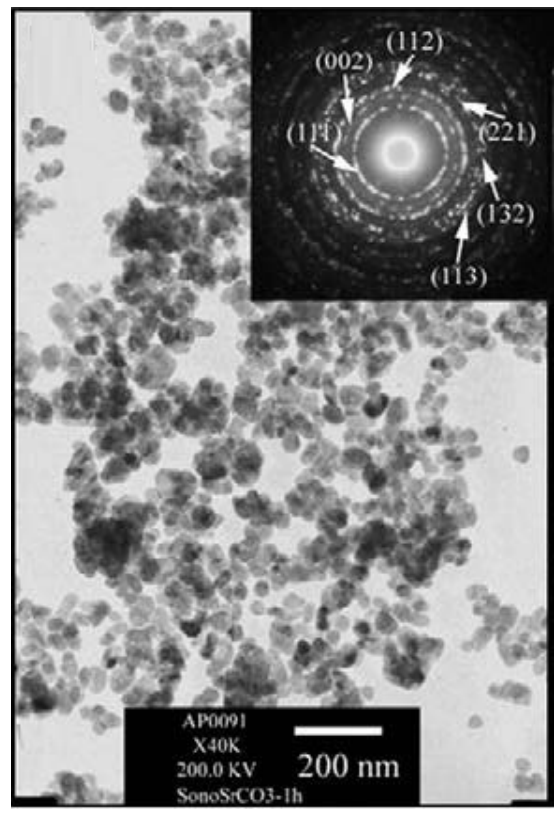

Fig. 18. TEM images and SAED patterns of as prepared $\mathrm{SrCO}_{3}$ [96]. Reproduced with permission of Elsevier.

\section{4. $\mathrm{Ca}(\mathrm{OH})_{2}$ and $\mathrm{CaO}$ nanostructures}

Tang et al. [107] prepared nano-CaO by thermal-decomposition method. They used $\mathrm{Ca}\left(\mathrm{NO}_{3}\right)_{2} .4 \mathrm{H}_{2} \mathrm{O}$ as precursor, $\mathrm{NaOH}$ aqueous solution as precipitant, and ethylene glycol as medium. The $\mathrm{Ca}(\mathrm{OH})_{2}$ that was obtained through the above mixing calcinated at $500^{\circ} \mathrm{C}$ and nano- $\mathrm{CaO}$ was prepared.

$\mathrm{CaO}$ Nanopods were synthesized [108] and also applied for high temperature $\mathrm{CO}_{2}$ capture. $\mathrm{CaCO}_{3}$ was precipitated from a saturated aqueous solution of $\mathrm{Ca}(\mathrm{OH})_{2}$ by bubbling through 


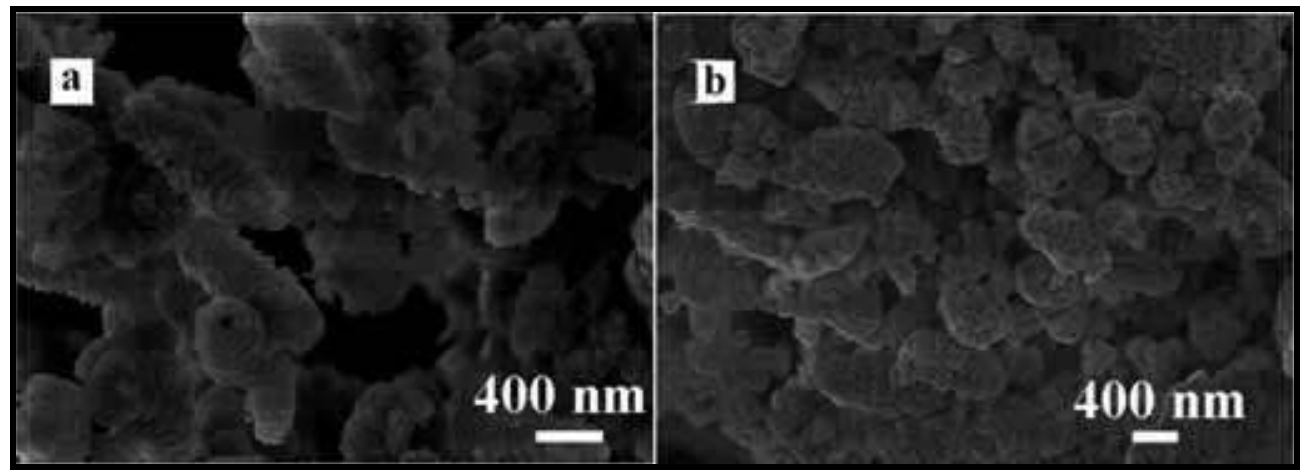

Fig. 19. FESEM images a) $\mathrm{CaCO}_{3}$ nanopods prepared in the presence of $\mathrm{P} 123$ surfactant and b) $\mathrm{CaO}$ derived from $\mathrm{CaCO}_{3}$ nanopods [108]. Reproduced with permission of American Chemical Society.

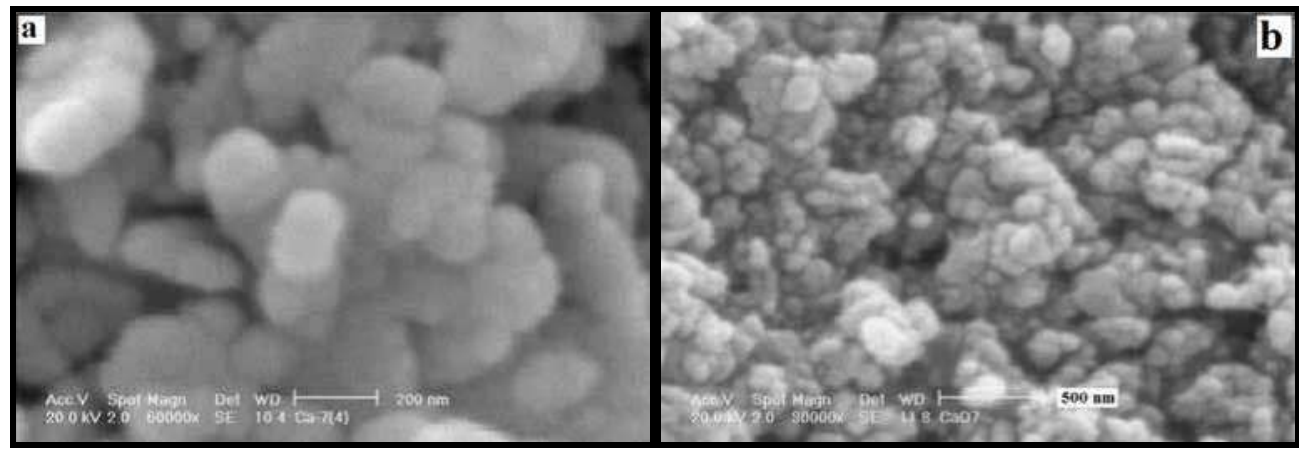

Fig. 20. SEM images of as prepared nanoparticles of a) $\mathrm{Ca}(\mathrm{OH})_{2}$ and b) $\mathrm{CaO}$ [109]. Reproduced with permission of Taylor \& Francis
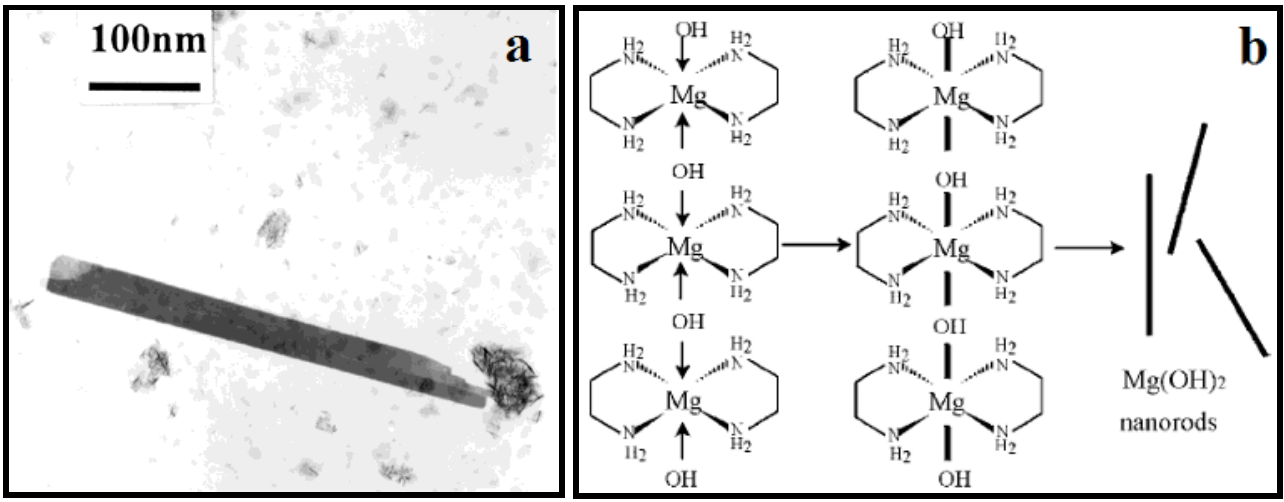

Fig. 21. a) TEM image and b) Schematic diagram of the mechanism of formation of $\mathrm{Mg}(\mathrm{OH})_{2}$ nanorods from $\mathrm{Mg}^{2+}$-ethylenediamine complexes [110]. Reproduced with permission of Wiley-VCH Verlag GmbH \& Co. KGaA. 
$\mathrm{CO}_{2}$ gas in the presence of the triblock copolymer, $\mathrm{P} 123\left(\mathrm{PEO}_{20} \mathrm{PPO}_{70} \mathrm{PEO}_{20}\right)$, an amphiphilic and neutral surfactant. The standard recipe involved dissolving $1.0 \mathrm{~g}$ of P123 in $100 \mathrm{~mL}$ of distilled water. This was done at room temperature with vigorous stirring. And then $\mathrm{CaO}$ were prepared for analysis by calcining the $\mathrm{CaCO}_{3}$ in a tube furnace at $700{ }^{\circ} \mathrm{C}$ for $3 \mathrm{~h}$ under $\mathrm{N}_{2}(1 \mathrm{~L} / \mathrm{min})$. FESEM images of precursor $\left(\mathrm{CaCO}_{3}\right)$ and $\mathrm{CaO}$ nanopods are shown in fig. 19. In the recent our study [109] we synthesized $\mathrm{Ca}(\mathrm{OH})_{2}$ and $\mathrm{CaO}$ nanostructures by simple sonochemical method. By reaction of calcium acetate and sodium hydroxide under ultrasound irradiation and also by using PVA and sodium nitrate as additives different morphologies of $\mathrm{Ca}(\mathrm{OH})_{2}$ are obtained. Then the prepared precursor is calcinated at $600{ }^{\circ} \mathrm{C}$ to synthesize of $\mathrm{CaO}$ nanoparticles. Fig. 20 shows a typical SEM image of both $\mathrm{Ca}(\mathrm{OH})_{2}$ and $\mathrm{CaO}$ nanoparticles.

\section{5. $\mathrm{Mg}(\mathrm{OH})_{2}$ and $\mathrm{MgO}$ nanostructures}

Li et al. [110] synthesized $\mathrm{Mg}(\mathrm{OH})_{2}$ nanorods from $\mathrm{Mg}$ powder and distilled water $(5 \mathrm{~mL})$ with ethylenediamine as the solvent at $180^{\circ} \mathrm{C}$ under pressure in an autoclave. Fig. 21 shows TEM image and also the preparation mechanism of $\mathrm{Mg}(\mathrm{OH})_{2}$ nanorods.

The Li group also prepared rod-like $\mathrm{Mg}(\mathrm{OH})_{2}$ nanocrystallites under hydrothermal conditions and converted it to $\mathrm{MgO}$ nanorods by thermal dehydration. Fig. 22 shows TEM images of as prepared $\mathrm{Mg}(\mathrm{OH})_{2}$ nanorods by hydrothermal method and also $\mathrm{MgO}$ nanorods that is obtained after thermal dehydration of $\mathrm{Mg}(\mathrm{OH})_{2}$ precursor.

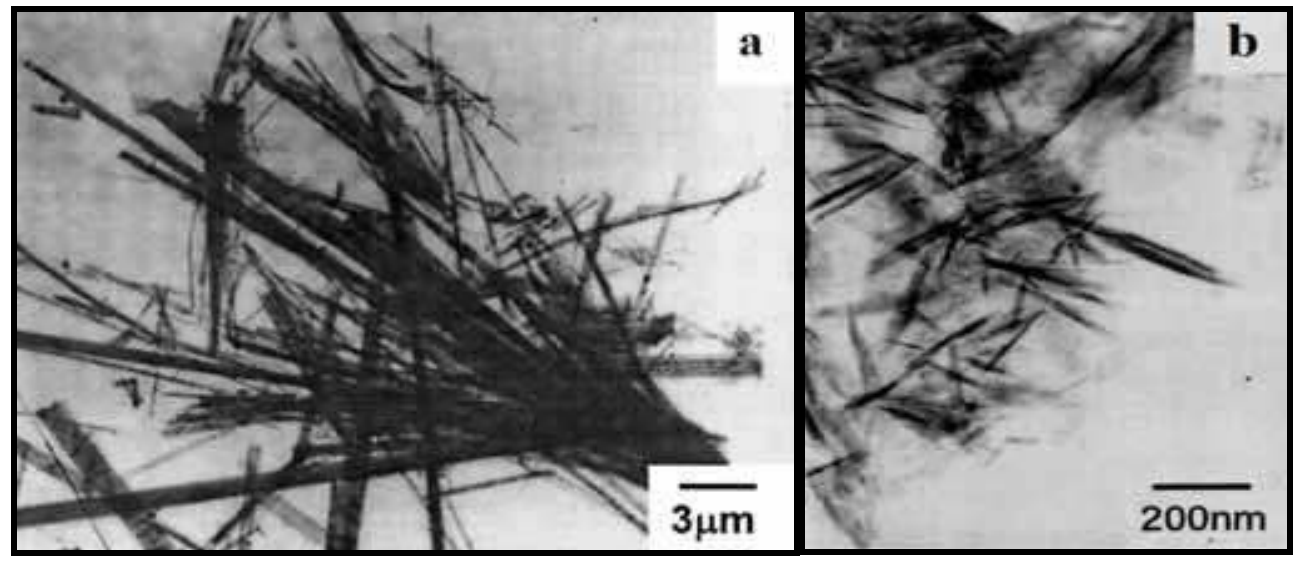

Fig. 22. TEM images of as prepared, a) $\mathrm{Mg}(\mathrm{OH})_{2}$ and b) $\mathrm{MgO}$ nanorods [111]. Reproduced with permission of Elsevier.

$\mathrm{Mg}(\mathrm{OH})_{2}$ nanotubes using $\mathrm{Mg}_{10}(\mathrm{OH})_{18} \mathrm{C}_{12} .5 \mathrm{H}_{2} \mathrm{O}$ nanowires as precursors by solvothermal method were synthesized [112]. Fig. 23 shows TEM image of $\mathrm{Mg}(\mathrm{OH})_{2}$ nanotubes that are obtained after solvothermal treatment of precursor in the presence of ethylenediamine as a solvent.

Ma et al. [113] investigated on formation of uniform $\mathrm{MgO}$ nanobelts from in situ $\mathrm{Mg}_{3} \mathrm{~N}_{2}$ precursor. $\mathrm{Mg}$ ribbons were put in an alumina boat inserted into a quartz tube reactor heated by a resistivity-heating furnace. The furnace temperature was raised to $650{ }^{\circ} \mathrm{C}$ at a ramp rate of $10{ }^{\circ} \mathrm{C} / \mathrm{min}$ and was held for $2 \mathrm{~h}$ under a constant nitrogen $\left(\mathrm{N}_{2}\right)$ flow in a 
flowing rate of 500 standard cubic centimeters per minute [113]. Fig. 24 shows SEM image of $\mathrm{MgO}$ nanobelts that are obtained from calcination of $\mathrm{Mg}_{3} \mathrm{~N}_{2}$ precursor under nitrogen/oxygen atmosphere $\left(\mathrm{N}_{2}=\mathrm{O}_{2}, 10: 1\right.$ in volumes).

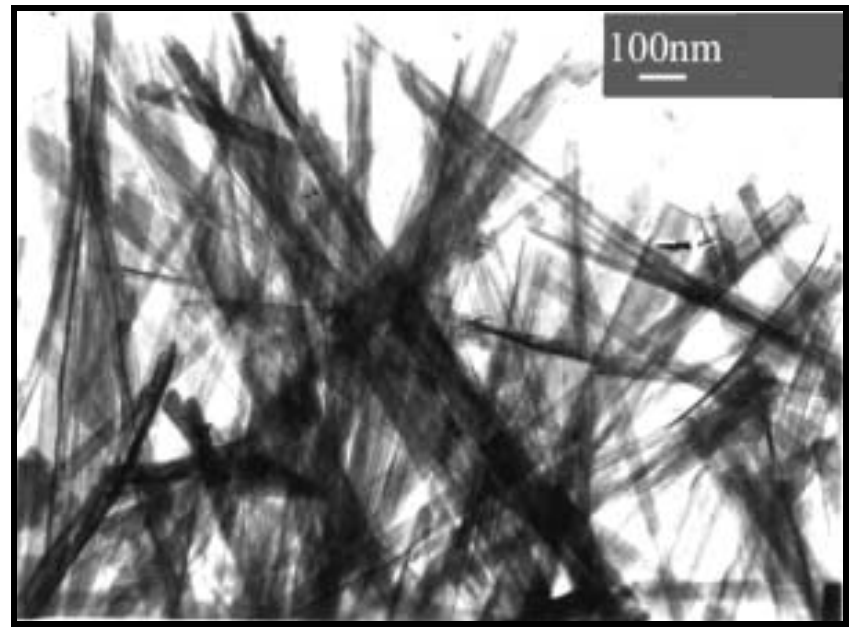

Fig. 23. TEM image of $\mathrm{Mg}(\mathrm{OH})_{2}$ nanotubes [112]. . Reproduced with permission of The Royal Society of Chemistry.

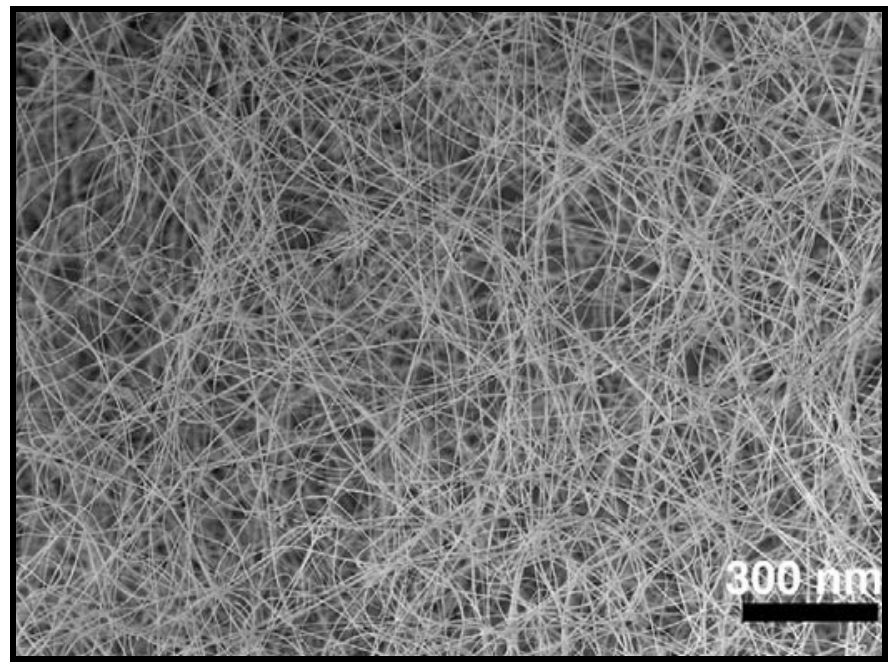

Fig. 24. SEM image of MgO nanobelts [113]. Reproduced with permission of Elsevier.

The size and morphologies of magnesium hydroxide nanoparticles precipitated in dilute aqueous solution was studied [114]. The samples were obtained by precipitation, at a controlled temperature, of a magnesium salt solution of concentration $0.75 \mathrm{~mol} / \mathrm{l}$ by addition of an alkaline solution $\left(\mathrm{NaOH}\right.$ or $\left.\mathrm{NH}_{4} \mathrm{OH}\right)$ of concentration $1.5 \mathrm{~mol} / \mathrm{l}$. Both 


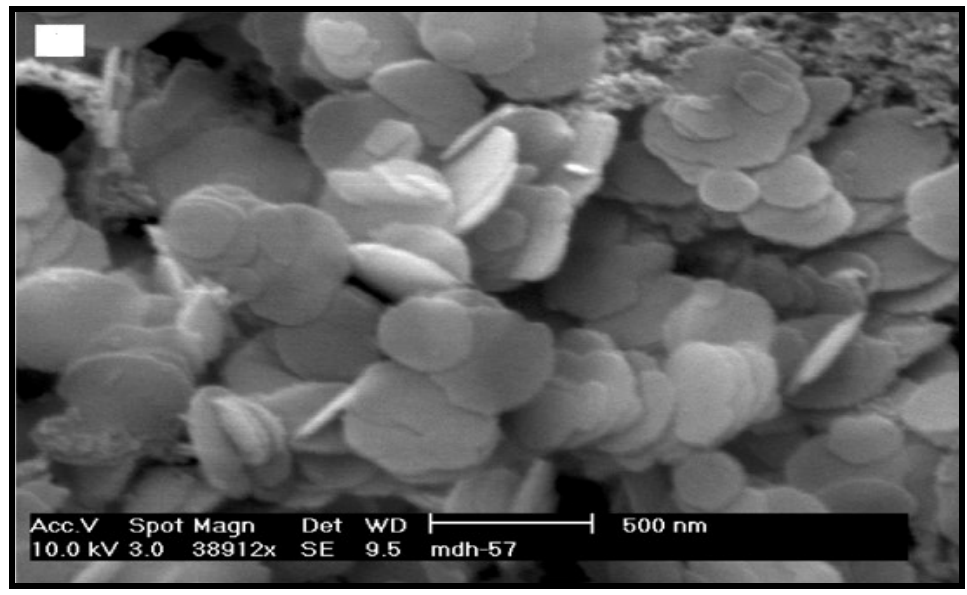

Fig. 25. SEM image of sample No. 4 that $\mathrm{Mg}\left(\mathrm{NO}_{3}\right)_{2}$ and $\mathrm{NH}_{4} \mathrm{OH}$ are used as $\mathrm{Mg}$ and base source, respectively [114]. Reproduced with permission of Elsevier.

reactants were simultaneously added into an ultrasonicated bath following the controlleddouble jet precipitation technique, with the help of peristaltic pumps working at a discharge of $3 \mathrm{ml} / \mathrm{min}$. A $450 \mathrm{ml}$ volume of alkaline water [pH 10, either $\mathrm{NH}_{4} \mathrm{OH}$ or $\mathrm{NaOH}$ ] initially present in the reactor, vigorous stirring was applied during the addition of the reactants, as well as during the ageing of the precipitate in the mother liquor. The suspension was allowed to age at the synthesis temperature for one day, then subsequently at room temperature for 2 days [114]. Fig. 25 shows SEM image of one of the samples that the platelet shape $\mathrm{Mg}(\mathrm{OH})_{2}$ is prepared by this method.

The growth of dumbbell-shaped $\mathrm{MgO}$ nanowhiskers was done by depositing $\mathrm{Mg}$ vapor generated via carbothermal reduction onto boron powder [115]. The whiskers and balls of these dumbbells have diameters of $50-150 \mathrm{~nm}$ and $1.4-2 \mathrm{~mm}$ respectively. The ball surface and the interface between ball and whisker are very smooth but the whisker surface is rough, which indicates that whiskers formed in advance and balls formed later by depositing silicon oxide and other vapor species onto the grown whisker surface. Fig.26 shows TEM image and SAED pattern of MgO dumbbell-shape whiskers.

$\mathrm{Qu}$ et al. [116] investigated on controlled growth of three morphological structures of magnesium hydroxide nanoparticles by wet precipitation method. It has been shown that the alkali solution concentration is of prime importance besides the complex dispersant: the use of lower concentration aqueous ammonia ( $5 \mathrm{wt} \%$ ) promotes the formation of needle or rod morphology, while the synthesis driven with higher concentration aqueous ammonia $(25 \mathrm{wt} \%)$ promotes the formation of platelet-shaped particles. Those behaviors are attributed to the mechanism of nuclei growth [116].

$\mathrm{MgO}$ nanostructured microspheres by an interfacial reaction in a solid-stabilized emulsion were reported and SEM image of obtained magnesium oxide is illustrated in Figure 27. The average diameter of the $\mathrm{MgO}$ microspheres was $5.3 \mu \mathrm{m}$, a little larger than that of their precursors. The diameter of the $\mathrm{MgO}$ microspheres was in a narrow range of 5.1 to $5.4 \mu \mathrm{m}$. The surfaces of the $\mathrm{MgO}$ microspheres also had leaf-like nanostructures with a leaf thickness of about $65 \mathrm{~nm}$ (measured by SEM images). 


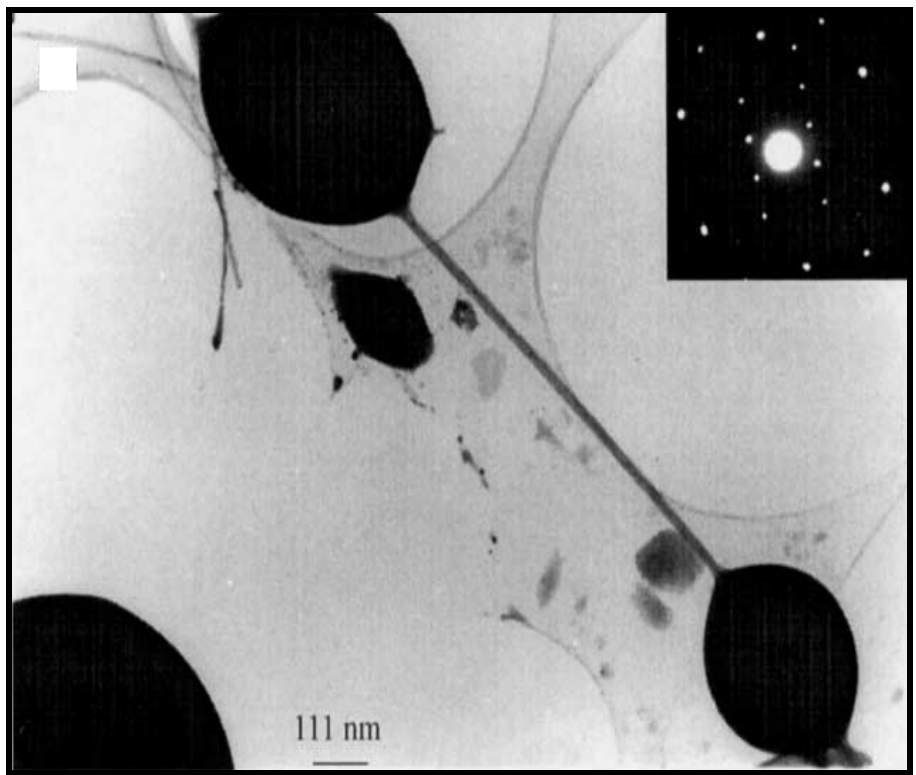

Fig. 26. TEM image and SAED pattern (inset) of dumbbell-shape whiskers of $\mathrm{MgO}$ [115]. Reproduced with permission of Elsevier.

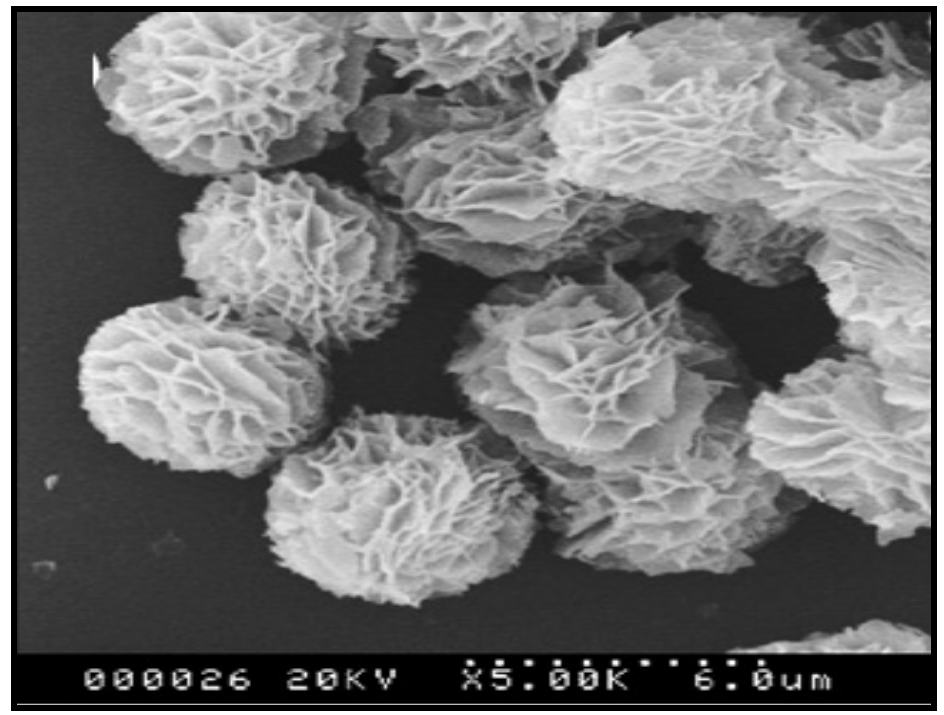

Fig. 27. SEM image of MgO microspheres [117]. Reproduced with permission of Elsevier.

Kim et al. [118] investigated on the growth of $\mathrm{MgO}$ nanowires by annealing treatment of Au-coated substrates. They applied thermal annealing treatment to the Au-coated substrates before they grow the $\mathrm{MgO}$ structures by a thermal evaporation of $\mathrm{MgB}_{2}$ powders. They 
obtained $\mathrm{MgO}$ nanowires by controlling the predeposition annealing temperature. The produced nanowires were of cubic $\mathrm{MgO}$ structures with diameters in the range of 40-200 $\mathrm{nm}$ (as illustrated in fig.28).

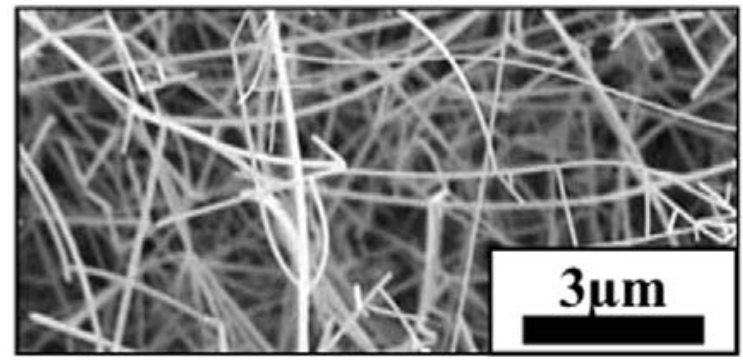

Fig. 28. SEM image of $\mathrm{MgO}$ nanowires with the predeposition annealing at $700{ }^{\circ} \mathrm{C}$ [118]. Reproduced with permission of Elsevier.

Nano-cube $\mathrm{MgO}$ was prepared by means of a domestic microwave oven [119]. The purpose of this preparation is to investigate a simple and rapid synthesis method using magnesium $(\mathrm{Mg})$ chip and steel-wool as starting materials for the growth of the $\mathrm{MgO}$ with nano-cube shape. Fig. 29 shows the HR-TEM image of a nano-cube $\mathrm{MgO}$. The resolved spacing of 0.21 $\mathrm{nm}$ corresponds to the (200) facets of $\mathrm{MgO}$. The surface of the nano-cube $\mathrm{MgO}$ is clean and atomically sharp without any sheathed amorphous phase [119].

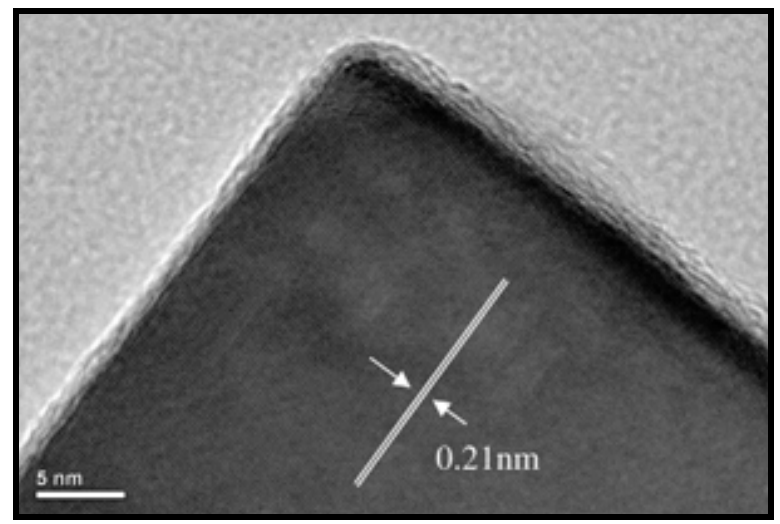

Fig. 29. HR-TEM image of the obtained MgO nano-cube [119]. Reproduced with permission of Elsevier.

Wu et al. [120] investigated on self-assembled growth of MgO nanosheet arrays via a microarc oxidation technique. They present a relatively simple method of fabricating aligned $\mathrm{MgO}$ sheet-like nanostructures on the surface of magnesium alloys via a promising microarc oxidation (MAO) technology. SEM observations reveal that many sheet-like structures form on the substrate surface. The nanosheets are slightly curved and approximately 300$400 \mathrm{~nm}$ in width and tens of nanometers in thickness. Most of them stick together to form nanosheet arrays. A large quantity of flower-like branched structures was also observed on the substrate. Fig. 30 shows these unique structures. 
Preparation of $\mathrm{Mg}(\mathrm{OH})_{2}$ nanoparticles in water-in-oil microemulsions [121] displays a platelet shape and the thickness is $c a .20 \mathrm{~nm}$. The particle size is larger than that of crystallites size because of the coalescing of crystallites. The particle size of different samples indicated that small particles were obtained in small micelles (at low $\omega_{0}$ ). The particle sizes from SEM images were seemingly larger than the mean sizes of micelles as a result of the coalescence of nanoparticles in different micelles caused by the collision of micelles [121]. Rezaei et al. [122] synthesized nanocrystalline magnesium oxide with high surface area. The pore size distribution, as calculated by the $B J H$ method from the desorption branch of the nitrogen isotherm, reveals that the $\mathrm{MgO}$ calcined at 600 and $700{ }^{\circ} \mathrm{C}$ contain small mesopores with pore size between $3.7-7.7 \mathrm{~nm}$ and large mesopores with a pore size of about $32.2 \mathrm{~nm}$. The former mesopores exist among small primary nanoparticles and the latter textural mesopores are formed by the aggregation of the small nanoparticles. The increase in calcination temperature influences the pore size distribution. It is seen that with increasing calcination temperature, the pore size distributions were shifted to larger sizes. The sample calcined at $800{ }^{\circ} \mathrm{C}$ showed a broad pore size distribution. In this sample the small mesopores were transformed to larger ones due to aggregation of the small nanoparticles at $800{ }^{\circ} \mathrm{C}$ [122]. TEM analysis of above samples shows that in this condition plate like structure of nanocrystalline $\mathrm{MgO}$ is prepared.

$\mathrm{Mg}(\mathrm{OH})_{2}$ nanostructures and $\mathrm{MgO}$ nanoparticles were prepared by sonochemical method [123]. Fig. 31a shows SEM image of MgO nanoparticles that is obtained by calcination of as prepared $\mathrm{Mg}(\mathrm{OH})_{2}$ nanostructures from reaction of $\mathrm{Mg}(\mathrm{OAc})_{2}$ and $\mathrm{NaOH}$ under ultrasound irradiation and also fig. 32b. shows SEM image of as prepared plate like structure of $\mathrm{Mg}(\mathrm{OH})_{2}$ by increasing ultrasound device power up to $150 \mathrm{~W}$. Particle size histogram was prepared for $\mathrm{MgO}$ particles after heating of $\mathrm{Mg}(\mathrm{OH})_{2}$ nanostructures at $400{ }^{\circ} \mathrm{C}$ for investigation of the size distribution of the nanoparticles. Most of the particles possess sizes in range from 55 to $75 \mathrm{~nm}$.

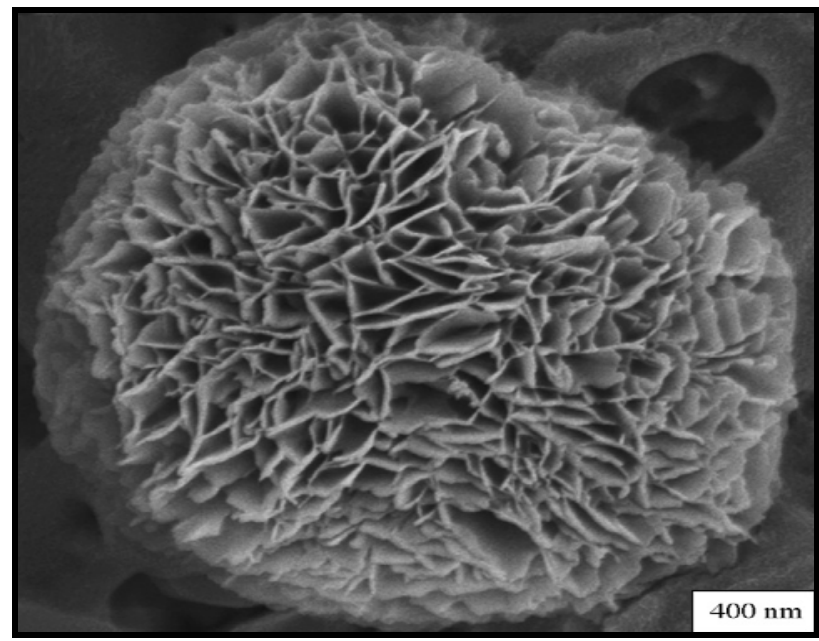

Fig. 30. SEM images of micrometer scale flower-like structures of MgO [120]. Reproduced with permission of Elsevier. 


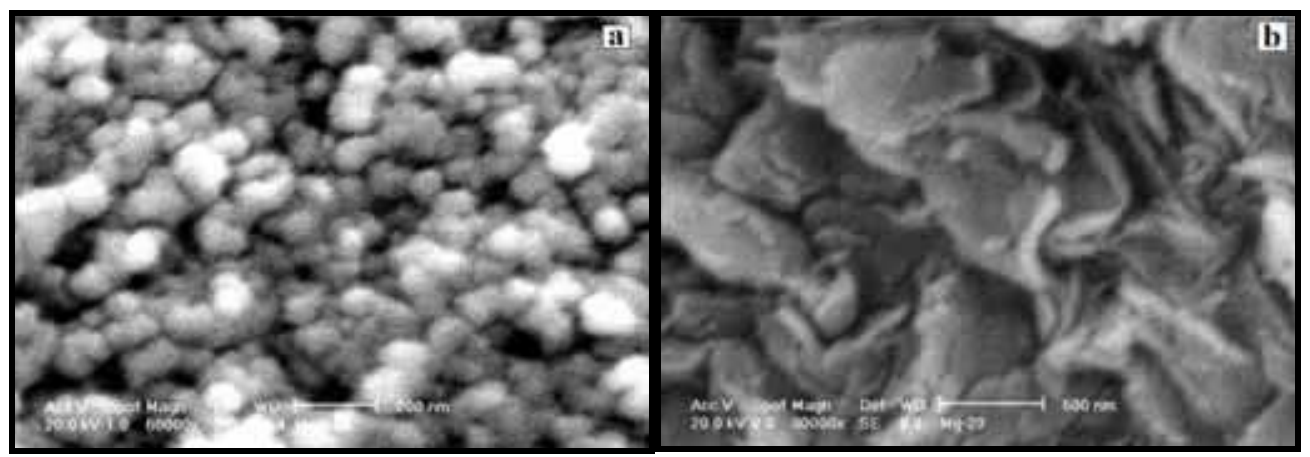

Fig. 31. SEM images of a) $\mathrm{MgO}$ nanoparticles and b) plate like structure of $\mathrm{Mg}(\mathrm{OH})_{2}[123]$. Reproduced with permission of Elsevier.

\section{Conclusion}

Because of importance of some of alkaline-earth metal compounds in industry and medicine, in this chapter we tried to summarize different methods that are used to synthesis nanostructures of $\mathrm{BaCO}_{3}, \mathrm{Sr}(\mathrm{OH})_{2}, \mathrm{SrCO}_{3}, \mathrm{Ca}(\mathrm{OH})_{2}, \mathrm{CaO}, \mathrm{Mg}(\mathrm{OH})_{2}$ and $\mathrm{MgO}$. As morphology of these compounds affect on application, so preparation methods have an important role on applicability of above compounds. Considering nanostructures discussed in this chapter, to obtain 1D nanostructure it can be used many compounds as template or stabilizer such as ethylenediamine, polyvinyl alcohol or some methods such as hydrothermal, reverse micelle, but in some cases as a nature of alkaline-earth metal just nanoparticles are obtained.

\section{Acknowledgments}

Supporting of this investigation by Tarbiat Modares University is gratefully acknowledged.

\section{References}

[1] W. Feng, L.-D. Sun, Y.-W. Zhang, C.-H. Yan, Coord. Chem. Rev. 254 (2010) 1038.

[2] L. Qi. Coord. Chem. Rev. 254 (2010) 1054.

[3] D.B. Kuang, A.W. Xu, Y.P. Fang, H.Q. Liu, C. Frommen, D. Fenske, Adv. Mater. 15 (2003) 1747.

[4] F. Kim, S. Connor, H. Song, T. Kuykendall, P.D. Yang, Angew. Chem. Int. Ed. 43 (2004) 3673.

[5] Sa Lv, Ping Li, Jie Sheng, Wendong Sun, Mater. Lett. 61 (2007) 4250.

[6] K. Omata, N. Nukui, T. Hottai, Y. Showa, M. Yamada, Catal. Commun. 5 (2004) 755.

[7] US Patent No. 5, 338, 706.

[8] J. Küther, G. Nells, R. Seshadri, M. Schaub, H.J. Butt, W. Tremel, Chem. Eur. J. 4 (1998)1834.

[9] J. Küther, R. Seshadri, G. Nells, W. Assenmacher, H.J. Butt, W. Mader, W. Tremel, Chem. Mater. 11 (1999) 1317. 
[10] J. Küther, M. Bartz, R. Seshadri, G.B.M. Vaughan, W.J. Tremel, Mater. Chem. 11 (2001) 503.

[11] M. Sastry, A. Kumar, C. Damle, S.R. Sainkar, M. Bhagwat, V. Ramaswamy, Cryst. Eng. Commun. 21 (2001) 1.

[12] D. Rautaray, S.R. Sainkar, M. Sastry, Langmuir 19 (2003) 888.

[13] L. Qi, K. Xi, J. Ma, Acta Chim. Sinica 1 (2003) 126.

[14] N.H. de Leeuw, J.A. Burton, Phys. Rev., B. 63 (2001) 195417.

[15] D. Kulkarni, I.E. Wachs, Appl. Catal. A. 237 (2002) 121.

[16] M. Boulouz, L. Martin, A. Boulouz, A. Boyer, Mater. Sci. Eng., B, Solid-State Mater. Adv. Technol. 67 (1999) 122.

[17] C.E. Curtis, L.M. Doney, J.R. Johnson, J. Am. Ceram. Soc. 37 (1954) 358.

[18] H. Doweidar, J. Non-Cryst. Solids. 277 (2000) 98.

[19] R. C. Whited, C. J Flaten and W. C. Walker. Solid State Commun. 13 (1973)1903.

[20] A. Yamasaki and T. Fujiwara, Phys. Rev. B. 66 (2002) 245108.

[21] A. M. Stoneham, J. Non-Cryst. Solids. 303 (2002) 114.

[22] M. C. Wu, J. S. Corneille, C. A. Estrada, J. W. He, D. W. Goodman, Chem. Phys. Lett. 182 (1991) 472.

[23] S. K. Shukla, G. K. Parashar, A. P. Mishra, P. Misra, B. C. Yadav, R. K. Shukla, L. M. Bali, G. C. Dubey, Sens. Actuators B. 98 (2004) 5.

[24] L.D. Zhang, J.M. Mo, Nanometer Materials, Science Press, Liaoning, 1994, pp. 303 (in Chinese).

[25] J. Sawai, H. Kojima, H. Igarashi, A. Hashimoto, S. Shoji, T. Sawaki, A. Hakoda, E. Kawada, T. Kokugan, M. Shimizu, World J. Microb. Biot. 16 (2000) 187.

[26] O. Yamamoto, J. Sawai, T. Sasamoto, Int. J. Inorg. Mater. 2 (2000) 451.

[27] O. B. Koper, J. S. Klabunde, G. L. Marchin, K. J. Klabunde, P. Stoimenov, L. Bohra, Curr. Microbiol. 44 (2002) 49.

[28] P. K. Stoimenov, R. L. Klinger, G. L. Marchin, K. J. Klabunde, Langmuir. 18 (2002) 6679.

[29] L. Huang, D. Li, Y. Lin, M. Wei, D. G. Evans, X. Duan, J. Inorg. Biochem. 99 (2005) 986.

[30] D. Kuang, A. Xu, Y. Fang, H. Ou, H. Liu, J. Cryst. Growth 244 (2002) 379.

[31] G. D. Rees, R. Evans-Gowing, S. J. Hammond, B. H. Robinson, Langmuir 15 (1999) 1993.

[32] C. Karagiozov, D. Momchilova, Chem. Eng. Process. 44 (2005) 115.

[33] K. Song, J. Kim, Powder Technol. 103 (2000) 268.

[34] J. Shmidt, TU Berlin, 2000.

[35] L. Li, Y. Chu, Y. Liu, L. Dong, L. Huo, F. Yang, Mater. Lett. 60 (2006) 2138.

[36] R. Strobel, M. Maciejewski, S. E. Pratsinis, A. Baiker, Thermochim. Acta 445 (2006) 23.

[37] L. Mädler, KONA 22 (2004) 107.

[38] S.E. Pratsinis, Prog. Energy Combust. Sci. 24 (1998) 197.

[39] R.N. Grass, W.J. Stark, Chem. Commun. (2005) 1767.

[40] M. Huber, W.J. Stark, S. Loher, M. Maciejewski, F. Krumeich, A. Baiker, Chem. Commun. (2005) 648.

[41] S. Loher, W.J. Stark, M. Maciejewski, A. Baiker, S.E. Pratsinis, D. Reichardt, F. Maspero, F. Krumeich, D. Günther, Chem. Mater. 17 (2005) 36.

[42] Y.G. Sun, Y.D. Yin, Brian T. Mayers, Thurston Herricks, Y.N Xia, Chem. Mater. 14 (2002) 4736. 
[43] J.G. Bai, Z.D. Xu, Y.F. Zheng, H.Y. Yin, Mater. Lett. 60 (2006) 1287.

[44] M-G. Ma, Y-J. Zhu, J-F. Zhu, Z-L. Xu, Mater. Lett. 61 (2007) 5133.

[45] G. Viau, F. Fiévet-Vincent, F. Fiévet, J. Mater. Chem. 6 (1996) 1047.

[46] P. Toneguzzo, G. Viau, O. Acher, F. Fiévet-Vincent, F. Fiévet, Adv. Mater. 10 (1998) 1032.

[47] G. Viau, R. Brayner, L. Poul, N. Chakroune, E. Lacaze, F. Fiévet-Vincent, F. Fiévet, Chem. Mater. 15 (2003) 486.

[48] C. Feldmann, H.O. Jungk, Angew. Chem. Int. Ed. 40 (2001) 359.

[49] J.F. Zhu, Y.J. Zhu, J. Phys. Chem., B 110 (2006) 8593.

[50] M-G. Ma, Y-J. Zhu, G-F. Cheng, Y-H. Huang, Mater. Lett. 62 (2008) 3110.

[51] V.K. Lamer, R.H. Dinegar, J. Am. Chem. Soc. 72 (1950) 4847.

[52] B.L. Cushing, V.L. Kolesnichenko, C.J. O'Connor, Chem. Rev. 104 (2004) 3893.

[53] J.A. Marqusee, J. Ross, J. Chem. Phys. 79 (1983) 373.

[54] S. Sugimoto, J. Colloid Interface Sci. 63 (1978) 16.

[55] D.B. Dadyburjor, E. Ruckenstein, J. Cryst. Growth 40 (1977) 279.

[56] R.L. Penn, J.F. Banfield, Geochim. Cosmochim. Acta 63 (1999) 1549.

[57] J.F. Banfield, S.A. Welch, H.Z. Zhang, T.T. Ebert, R.L. Penn, Science 289 (2000) 751.

[58] M. A. Alavi, A. Morsali, Ultrason. Sonochem. 15 (2008) 833.

[59] K.S. Suslick, Science 247 (1990) 1439.

[60] D.N. Srivastava, N. Perkas, G.A. Seisenbaeva, Y. Koltypin, V.G. Kessler, A. Gedanken, Ultrason. Sonochem. 10 (2003) 1.

[61] X.L. Zhang, Y.H. Kim, Y.S. Kang, Curr. Appl. Phys. 6 (2006) 796.

[62] A. Askarinejad, A. Morsali, Mater. Lett. 62 (2008) 478.

[63] A. Askarinejad, A. Morsali, Ultrason. Sonochem. 16 (2009) 124.

[64] N. Soltanzadeh, A. Morsali, Polyhedron 281 (2009) 1343.

[65] A. Aslani, A. Morsali, V. T. Yilmaz, C. Kazak, J. Mol. Struct. 929 (2009) 187.

[66] S. Khanjani, A. Morsali, J. Mol. Struct. 935 (2009) 27.

[67] A. Morsali, H. H. Monfared, A. Morsali, Inorg. Chim. Acta, 362 (2009) 3427.

[68] A. Askarinejad, A. Morsali, Chem. Eng. J. 153 (2009) 183.

[69] A. Aslani, A. Morsali Inorg. Chim. Acta, 362 (2009) 5012.

[70] Z. R. Ranjbar, A. Morsali, J. Mol. Struc. 936 (2009) 206.

[71] N. Soltanzadeh, A. Morsali, Ultrason. Sonochem. 17(2010) 139.

[72] M. J. Soltanian Fard-Jahromi, A. Morsali, Ultrason. Sonochem. 17(2010) 435.

[73] H. Sadeghzadeh, A. Morsali, P. Retailleau, Polyhedron, 29 (2010) 925.

[74] H. Sadeghzadeh, A. Morsali, Ultrason. Sonochem. In Press, Available online 24 February 2010.

[75] H. Sadeghzadeh, A. Morsali, V. T. Yilmaz, O. Büyükgüngör Ultrason. Sonochem, 17 2010) 592.

[76] A. R. Abbasi, A. Morsali, Ultrason. Sonochem. 17 (2010) 572.

[77] H. Sadeghzadeh, A. Morsali, V. T. Yilmaz, O. Büyükgüngör, Inorg. Chim. Acta, 363 (2010) 841.

[78] M. Khanpour, A. Morsali, P. Retailleau, Polyhedron, 29 (2010) 1520.

[79] A. R. Abbasi, A. Morsali Ultrason. Sonochem. 17 (2010) 704.

[80] S. Khanjani, A. Morsali, J. Mol. Liq. 153 (2010) 129.

[81] Z. Darvishi, A. Morsali, Ultrason. Sonochem. In Press, Available online 4 June 2010. 
[82] A. R. Abbasi, A. Morsali, Ultrason. Sonochem. In Press, Available online 30 June 2010.

[83] M. S. Yazdan Parast, A. Morsali, Ultrason. Sonochem. In Press, Available online 6 July 2010.

[84] L. Aboutorabi, A. Morsali, Ultrason. Sonochem. In Press, Available online 27 July 2010.

[85] L. Aboutorabi, A. Morsali, Inorg. Chim. Acta, 363 (2010) 2506.

[86] H. Sadeghzadeh, A. Morsali, CrystEngComm. 12 (2010) 370.

[87] A. Gedanken, Ultrason. Sonochem. 11 (2004) 47.

[88] V.G. Pol, A. Gedanken, J. Chem. Mater. 15 (2003) 1111.

[89] T. Gao, Q.H. Li, T.H.Wang, Chem. Mater. 17 (2005) 887.

[90] N.A. Dhas, A. Zaban, A. Gedanken, Chem. Mater. 11 (1999) 806.

[91] T. Gao, T.H.Wang, Chem. Commun. 22 (2004) 2558.

[92] N.A. Dhas, Appl. Phys. Lett. 72 (1998) 2514.

[93] Q. Zhang, C. Chen, L. Fang, Mater. Chem. Phys. 111 (2008) 191.

[94] S. Lv, J. Sheng, S. Zhang, W. Sun, Mater. Res. Bull. 43 (2008) 1099.

[95] X.L. Hu, Y.J. Jie, Langmuir 20 (2004) 1521.

[96] T. Thongtem, N. Tipcompor, A. Phuruangrat, S. Thongtem, Mater. Lett. 64 (2010) 510.

[97] K.W. Andrews, D.J. Dyson, S.R. Keown. Interpretation of electron diffraction patterns, 183 New York: Plenum Press; 1971.

[98] Powder Diffract. File, JCPDS-ICDD, 12 Campus Boulevard, Newtown Square, PA 179 19073-3273, U.S.A. (2001).

[99] M. Cao, X. Wu, X. He, C. Hu, Langmuir 21 (2005) 6093.

[100] J. Du, Z. Liu, Z. Li, B. Han, Y. Huang, J. Zhang, Microporous Mesoporous Mater. 83 (2005) 145.

[101] (a) T. Welton, Chem. Rev. 99 (1999) 2071;

(b) K.R. Seddon, Nat. Mater. 2 (2003) 363.

[102] S. Li, H. Zhang, J. Xu, D. Yang, Mater. Lett. 59 (2005) 420.

[103] J. Yu, H. Guo, B. Cheng, J. Solid State Chem. 179 (2006) 800.

[104] M-G. Ma, Y-J. Zhu, Mater. Lett. 62 (2008) 2512.

[105] G. Guo, G. Yan, L. Wang, J. Huang, Mater. Lett. 62 (2008) 4018.

[106] M. A. Alavi, A. Morsali, Ultrason. Sonochem. 17 (2010) 132.

[107] Z-X. Tang, D. Claveau, R. Corcuff, K. Belkacemi, J. Arul, Mater. Lett. 62 (2008) 2096.

[108] Z.Yang, M. Zhao, N. H. Florin, A. T. Harris, Ind. Eng. Chem. Res. 48 (2009) 10765.

[109] M. A. Alavi, A. Morsali, J. Exp. Nanosci. 5 (2010) 93.

[110] Y. Li, M. Sui, Y. Ding, G. Zhang, J. Zhuang, and C. Wang, Adv. Mater. 12 (2000) 818.

[111] L. Yan, J. Zhuang, X. Sun, Z. Deng, Y. Li, Mater. Chem. Phys. 76 (2002) 119.

[112] W. Fan, S. Sun, L. You, G. Cao, X. Song, W. Zhang and H. Yu, J. Mater. Chem. 13 (2003) 3062.

[113] R. Ma, Y. Bando, Chem. Phys. Lett. 370 (2003) 770.

[114] C. Henrist, J.-P. Mathieu, C. Vogels, A. Rulmont, R. Cloots, J. Cryst. Growth 249 (2003) 321.

[115] Y. Chen, J. Li, Y. Han, X. Yang, J. Dai, Ceram. Int. 29 (2003) 663.

[116] J. Lv, L. Qiu, B. Qu, J. Cryst. Growth 267 (2004) 676.

[117] Y. He, Mater. Lett. 60 (2006) 3511.

[118] H. W. Kim, S. H. Shim, Chem. Phys. Lett. 422 (2006) 165. 
[119] N. Takahashi, Solid State Sci. 9 (2007) 722.

[120] T. Qiu, X.L. Wu, F.Y. Jin, A.P. Huang, P.K. Chu, Appl. Surf. Sci. 253 (2007) 3987.

[121] J. Wu, H. Yan, X. Zhang, L. Wei, X. Liu, B. Xu, J. Colloid Interface Sci. 324 (2008) 167.

[122] F. Meshkani, M. Rezaei, Powder Technol. 196 (2009) 85.

[123] M.A. Alavi, A. Morsali, Ultrason. Sonochem. 17 (2010) 441. 


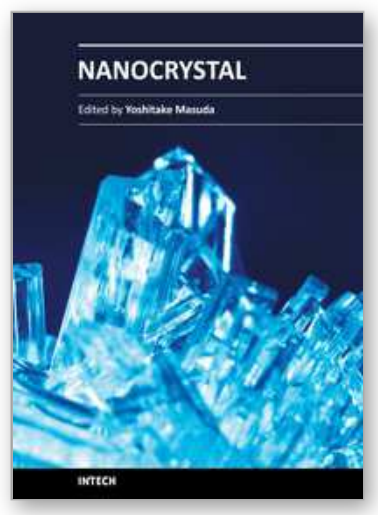

\author{
Nanocrystal \\ Edited by Dr. Yoshitake Masuda
}

ISBN 978-953-307-199-2

Hard cover, 494 pages

Publisher InTech

Published online 28, June, 2011

Published in print edition June, 2011

We focused on cutting-edge science and technology of Nanocrystals in this book. â€œNanocrystalâ€ is expected to lead to the creation of new materials with revolutionary properties and functions. It will open up fresh possibilities for the solution to the environmental problems and energy problems. We wish that this book contributes to bequeath a beautiful environment and valuable resources to subsequent generations.

\title{
How to reference
}

In order to correctly reference this scholarly work, feel free to copy and paste the following:

Mohammad Amin Alavi and Ali Morsali (2011). Alkaline-Earth Metal Carbonate, Hydroxide and Oxide NanoCrystals Synthesis Methods, Size and Morphologies Consideration, Nanocrystal, Dr. Yoshitake Masuda (Ed.), ISBN: 978-953-307-199-2, InTech, Available from: http://www.intechopen.com/books/nanocrystal/alkalineearth-metal-carbonate-hydroxide-and-oxide-nano-crystals-synthesis-methods-size-and-morpholo

\section{INTECH}

open science | open minds

\author{
InTech Europe \\ University Campus STeP Ri \\ Slavka Krautzeka 83/A \\ 51000 Rijeka, Croatia \\ Phone: +385 (51) 770447 \\ Fax: +385 (51) 686166 \\ www.intechopen.com
}

\author{
InTech China \\ Unit 405, Office Block, Hotel Equatorial Shanghai \\ No.65, Yan An Road (West), Shanghai, 200040, China \\ 中国上海市延安西路65号上海国际贵都大饭店办公楼 405 单元 \\ Phone: +86-21-62489820 \\ Fax: $+86-21-62489821$
}


(C) 2011 The Author(s). Licensee IntechOpen. This chapter is distributed under the terms of the Creative Commons Attribution-NonCommercialShareAlike-3.0 License, which permits use, distribution and reproduction for non-commercial purposes, provided the original is properly cited and derivative works building on this content are distributed under the same license. 